\title{
Toward a Theory of Extended Contact: The Incentives and Opportunities for Bridging Across Network Communities
}

\section{Citation}

Sytch, Maxim, Adam Tatarynowicz, and Ranjay Gulati. "Toward a Theory of Extended Contact: The Incentives and Opportunities for Bridging Across Network Communities." Organization Science 23 (November-December 2012): 1658-1681.

\section{Published Version}

http://orgsci.journal.informs.org/content/23/6/1658.abstract

\section{Permanent link}

http://nrs.harvard.edu/urn-3:HUL.InstRepos:10996806

\section{Terms of Use}

This article was downloaded from Harvard University's DASH repository, and is made available under the terms and conditions applicable to Open Access Policy Articles, as set forth at http:// nrs.harvard.edu/urn-3:HUL.InstRepos:dash.current.terms-of-use\#OAP

\section{Share Your Story}

The Harvard community has made this article openly available.

Please share how this access benefits you. Submit a story.

\section{Accessibility}


Toward a Theory of Extended Contact:

The Incentives and Opportunities for Bridging Across Network Communities

\author{
Maxim Sytch \\ Ross School of Business \\ University of Michigan \\ 701 Tappan St. \\ Ann Arbor, MI 48109
}

Ph: 734.467.1055; Fax: 734.764.2555764.2555

msytch@,bus.umich.edu

Adam Tatarynowicz

Department of Organization and Strategy

Tilburg University

P.O. Box 90153

5000 LE Tilburg

a.tatarynowicz@tilburguniversity.edu

Ranjay Gulati

Harvard Business School

Harvard University

Morgan Hall, Soldiers Field,

Boston, MA 02163

Ph: 617.495.6327 Fax: 617.496.6568

rgulati@,hbs.edu

\title{
Forthcoming in Organization Science
}

\footnotetext{
- The authors contributed equally to this research. We would like to thank Wayne Baker, Joel Baum, Jerry Davis, Michael Jensen, Chris Marquis, Andrew Shipilov, Olav Sorenson, Noam Wasserman, Jim Westphal, and Valery Yakubovich for helpful comments and discussions of this paper.
} 


\begin{abstract}
This study investigates the determinants of bridging ties within networks of interconnected firms. Bridging ties are defined as non-redundant connections between firms located in different network communities. We highlight how firms can enter into these relationships due to the incentives and opportunities for action that are embedded in the existing network structure. Specifically, we propose that the dynamics of proximate network structures, which reflect firms' and their partners' direct connections, affect the formation of bridging ties by shaping the value-creation and value-distribution incentives for bridging. We also argue that the evolving global network structure affects firms' propensity to form bridging ties by shaping the structural opportunities for bridging. We test our theory using the network of partnership ties among firms in the global computer industry from 1991 to 2005. We find support for structural incentives and opportunities as influential precursors of bridging ties.
\end{abstract}

\title{
INTRODUCTION
}

Over the past two decades, a rich stream of research has highlighted the importance of social actors' embeddedness in a web of social relations (Baker 1984; Granovetter 1985; Mizruchi and Galaskiewicz 1993; Zaheer and Bell 2005). Because information is asymmetrically distributed in markets and evaluating the resource endowments, reliability, and competence of potential partners is often difficult, actors tend to rely on referrals and reputational lock-ins offered by their current partners (Gulati 1995). As a result, actors reach out to their partners' partners and form tight and densely connected network communities. These communities crystallize as dense structural groups within the network in which actors are connected more to each other than to other actors in the system (Knoke 2009; Wellman 1979). The formation of network communities is further reinforced by actors' tendencies for homophilous attachment (Ahuja et al. 2009; McPherson et al. 2001; Powell et al. 2005) and the supporting role of geographical proximity in forging and sustaining social interaction (Sorenson and Stuart 2001). In many social settings, however, we observe bridging ties that interlink these network communities into a globally-connected system (e.g., Davis et al. 2003; Watts 1999). This study aims to understand the dynamics of extended contact in networks by exploring the determinants of bridging relationships.

Bridging ties occupy an important place in the architecture of social systems. In addition to determining the outcomes of individual and corporate actors (e.g., McEvily et al. 2011), they have critical implications for the structure and performance of global systems. Without bridging ties, social structures emerge as fragmented and incoherent (Granovetter 1983; Rosenkopf and Padula 2008). In contrast, bridges interlink distinct communities of actors and enable any two actors to reach one another quickly, thereby serving as key inputs into the structure of small worlds that characterizes many social settings (Baum et al. 2003; Davis et al. 2003; Uzzi and Spiro 2005). For their role in providing critical shortcuts through social space, bridging ties have been credited with enabling 
diverse systems to spread innovations, fads and fashions, and even diseases more quickly, and to coordinate collective action more effectively (Macy 1990; Rogers 2003; Watts and Strogatz 1998).

Perhaps inspired by the many tangible benefits of bridging ties, scholars have overwhelmingly gravitated to analyzing the implications of bridges for social actors and social systems. Notwithstanding the value of these insights, this virtually exclusive focus on the outcomes of bridging ties has led current studies to overlook the determinants of bridging ties. ${ }^{1}$ Yet, as Aldrich (1982: 282) noted, "a successful social analysis . . cannot take social structures as given, but rather must be able to account for their origins and their persistence." Such calls to avoid considering network structures as "given" and instead look at them as systematic objects of inquiry have been echoed in a number of studies (e.g., Ahuja et al. 2011; Powell et al. 2005; Salancik 1995).

Understanding the determinants of bridging ties is important for several reasons. The first is phenomenological: if entering into bridging ties indeed generates the benefits documented in extant research, then it is important to understand why we observe such heterogeneity in actors' entering into bridging relationships in many social systems. The second is theoretical. By gaining a deeper understanding of which parties are more likely to enter into bridging ties and the factors that may account for systematic variation in their propensities to do so, scholars can connect the emergent network structures more compellingly to individual and collective actions and outcomes.

In this paper, we study the determinants of extended contact by exploring how evolving social structure can exert enabling and constraining pressures on actors' propensity to form bridging ties (Burt 1982; Giddens 1984; Zaheer and Soda 2009). This effect is explored in two forms. First, we investigate how proximate network structures, which reflect actors' and their alters' direct connections, can determine the actors' incentives for entering into bridging relationships. In a system of interorganizational exchange relationships, this effect may occur because the proximate network affects value-creation and value-distribution incentives for bridging. With respect to the value-creation incentives, we explore how actors' existing bridging and local ties shape actors'

\footnotetext{
${ }^{1}$ Here and throughout the paper we differentiate between bridging ties (connecting actors from different network communities) and local ties (connecting actors within the same network community). The term "local ties" is akin to "closure ties" (Baum et al. 2010) and "ties to redundant contacts" (Burt 1992) in that they all emphasize redundancy of these contacts. "Closure ties" and "ties to redundant contacts", however, have been typically operationalized at the ego network level, by differentiating between ties in open and closed triads. Identifying "local ties," in contrast, takes into consideration the community structure of the network by isolating ties that run within such communities. This approach builds on the theoretical premise that information, knowledge, and resources are more heterogeneous between rather than within network communities. It thus differs from the perspective that associates heterogeneity with two simply unconnected contacts, which can reside in the same community or in different communities.
} 
anticipated benefits from using newly formed bridging ties toward creating recombinant innovations. Regarding value-distribution incentives, we hypothesize that partners' new bridging ties can change the dependence status quo and how value is distributed between the ego and its partners, thus causing the ego to respond (e.g., Aldrich 1979; Cook 1977; Kim et al. 2004; Pfeffer and Salancik 1978). Taken together, the effects of incentives illustrate how the evolving social structure exerts an indirect effect on actors' propensities to form new bridging ties, by conditioning the actors' economic interests. In the second form of this effect, we explore how the evolving global network topology - which reflects the network structure of the entire social or economic setting - can change the availability of bridging contacts. Since the availability of new bridging contacts determines the opportunity space for bridging, the dynamics of the global network thus exert a direct effect in terms of enabling or constraining actors' formation of bridging ties.

In exploring the determinants of bridging ties, this paper contributes to the studies of social embeddedness of economic action (Burt 2005; Granovetter 1985; Podolny 1994; Zuckerman 2004) and to the work on the evolutionary dynamics of networks (Gulati and Gargiulo 1999; Rosenkopf et al. 2001). First, we highlight that bridging ties, which are observed in many social contexts, should not be considered as "given". Rather, their determinants should be considered as an important research question in and of itself. We show that bridging ties may emerge from a complex set of determinants including actors' both proximate network structures and the features of the global network in which the actors are embedded. Second, our work contributes to the structural theory of action (Burt 1982; Coleman 1990; Lin 2001; Zaheer and Soda 2009) by explicating how network structures may enable or constrain action. One implication lies in decomposing the effect of social structure on action into its constituent indirect and direct effects. The indirect effect stems from the fact that proximate network structures can shape the advantages of value creation and distribution in exchange systems, thus creating incentives for action. The direct effect, in turn, stems from the evolution of the global network topology. Its evolutionary dynamics can determine the distribution of structural opportunities for bridging and thus directly constrain or enable action. Taken together, these effects demonstrate how both proximate and global network structures can influence actors' behaviors. Finally, we contribute to studies of complex social systems, in which bridging ties often play a critical role by binding actors together into a small world system (e.g., Davis et al. 2003; Gulati et al. 2011). Exploring the determinants of bridging ties can thus 
shed light on the evolutionary dynamics of complex networks, as well as on the various forms of integration and divides that characterize many technological, organizational, and political systems (Feld and Carter 1998).

This study focuses on firms in the global computer industry and their network of partnership ties from 1991 to 2005. Given our research question, this empirical context is appealing for two reasons. First, in a domain characterized by a general paucity of reliable longitudinal data, partnership networks are unique in that they represent a rich setting for dynamic analyses of social structure (e.g., Gulati and Gargiulo 1999; Powell et al. 2005; Uzzi 1996). Second, bridging ties are critical in the computer industry because firms' survival in this sector often depends on access to and recombination of novel, heterogeneous resources and knowledge, which are essential for creating commercially promising innovations. Because some purposive orientation can be necessary to establish the effect of social structure on action even under the most severe structural constraints (Giddens 1984: 179), it is precisely in this context that we expect to observe the constraining and enabling effects of social structure on firms' forming new bridging ties.

\section{PARTNERSHIP NETWORKS AND BRIDGING TIES IN THE COMPUTER INDUSTRY}

Extant research has suggested that bridging collaborations may be more important in those contexts, where actors are more concerned with acquiring new resources than with preserving their existing resource base (Lin 2001: 45-54). One such context is the knowledge-intensive computer industry, in which access to front-line,

heterogeneous knowledge and resources is crucial for firms' outcomes and survival (Eisenhardt and Tabrizi 1995; Rowley et al. 2000). Given the highly competitive nature of the computer industry and computer firms' focus on securing proprietary knowledge assets, bridging ties are likely to offer a particularly ample basis for competitive advantage in this setting. Since partnerships generally represent durable and embedded forms of interorganizational exchange and serve as invaluable "pipes" for the flows of information and knowledge (Podolny 2001), bridging partnerships can be instrumental in enabling the flows of novel and heterogeneous knowledge that determines a firm's ability to design and deliver breakthrough innovations. These flows can for instance relate to specialized knowledge about different computing platforms, hardware components, and applications, or provide insights regarding new market opportunities, customer needs, and distribution channels (Dedrick and Kraemer 2005). Furthermore, in the highly competitive setting of a high-tech industry, access to 
diverse knowledge pools may be largely unavailable outside of the interorganizational partnerships that serve as a basis of particularly deep and rich interactions among firms (Owen-Smith and Powell 2004).

To validate these claims empirically, we conducted an extensive set of computer simulations in which we modeled firms' propensity to form bridging partnerships. We subsequently compared the emergent networks to existing networks observed across a wide range of real industrial settings. We used the degree of correspondence between the predicted and the observed network structures to approximate computer firms' propensity to enter into bridging ties compared to firms in other industries. Our results indicate that firms in the computer industry indeed have a far greater propensity to enter into bridging ties compared to firms in other settings, including the auto industry, new materials and chemicals. ${ }^{2}$

Notwithstanding the general importance of extended contact for computer firms, bridging ties became particularly critical around the time of our study between 1991 and 2005. By the early 1990s, the computer industry had entered a decade of specialization where large and strongly integrated companies, such as DEC or Olivetti, were unable to compete against smaller, more specialized manufacturers. The "new computer industry" (Grove 1996) that emerged as a result of these structural changes featured a growing variety of independent and technologically distinct companies. These firms focused either on supplying complementary technologies along the value chain or pursuing horizontal diversification. Echoing the latter trend, industry research has indicated that collaboration among sellers of substitutes rose rapidly in the 1990s (Bresnahan 2000).

The new structure of the computer industry gave rise to two distinct collaborative trends. First, firms began to collaborate intensively with co-specialized partners in order to exploit joint capabilities in a given technology or process. For instance, firms specializing in computer storage, such as hard disks or floppy drives, formed partnerships with other storage firms (Malerba and Orsenigo 1996). These relationships led to the emergence of distinct pockets of production and innovation in the partnership network and crystallized into dense network communities. Second, due to the growing complexity, complementarity, and modularity of computer products (Bresnahan 1999), firms also increasingly saw the need to recombine their knowledge and skills across different technologies, and thus form ties outside of their network communities. One manifestation of this trend was that firms began to pursue extended contact around distinct computing systems, or platforms.

\footnotetext{
${ }^{2}$ Detailed results of these tests are available from the authors upon request.
} 
These bridging contacts were used by firms not only to gain access to complementary technologies, but also ensure that their products relied on common standards and communication protocols (e.g., the Internet protocol). One such platform emerged in the early 1990s around Microsoft Windows and also involved, besides Microsoft, a large set of partners that specialized in supplying complementary hardware, applications, and services (Bresnahan 1999). Underscoring the trend towards bridging collaboration, a representative of Microsoft noted, "In fact, the computer industry would cease to function if developers of complementary products that interact with one another in technically complex ways could not talk about how those products interact, now and in the future" (Bresnahan 2000: 19).

In addition to the impact of standards and platforms, the formation of bridging ties was sustained by the growing modularity of the computer technology, in particular the PC (Bresnahan and Greenstein 1999). The modular design of the PC allowed a variety of manufactures to supply similar and interchangeable components to the same market. While this model positioned IBM as one of the central bridging firms in the industry's collaborative structure, it also fostered a global network architecture that consisted of multiple network communities and bridging ties between them, through which companies could supply and acquire inputs as well as search for possible alternatives.

In sum, bridging ties are essential for firms' survival and success in the dynamic and fast-paced computer industry. Given that the formation of these ties is underpinned by a strong sense of economic purpose, we can plausibly anticipate social structure to affect the firms' propensity to do so by creating more or less disadvantageous conditions for action. This context, therefore, is particularly conducive to testing the effects of structural incentives and opportunities on the formation of new bridging ties. ${ }^{3}$

\section{THEORY AND HYPOTHESES}

\section{Bridging Relationships in the Study of Social Structure}

\footnotetext{
${ }^{3}$ Existing work on the computer industry indicates that the pursuit of bridging ties began to decline around 2000 (Gulati et al. 2011). This occurred in response to three sets of developments: (i) the homogenization of the knowledge space and the subsequent decline in returns from bridging collaboration; (ii) the increased uncertainty regarding extended contact following the collapse of the New Economy; and (iii) the emergence of self-contained networks and competing communities of firms. In this era, many firms opted for more incremental or even inward-oriented innovation models. We account for these historical trends in our research by controlling for time-trends.
} 
Three related theoretical conceptualizations incorporate a strong focus on bridging ties: weak ties, structural holes, and range. Granovetter (1973: 1361) conceptualized "weak ties" in terms of "the amount of time, the emotional intensity, the intimacy (mutual confiding), and the reciprocal services which characterize the tie". The central feature of his argument, however, was that tie strength inversely correlates with spanning distinct network communities and that "the significance of weak ties, then, would be that those which are local bridges (emphasis added) create more, and shorter, paths [through the network]" (Granovetter 1973: 1365). The "structural holes" conceptualization, in turn, focused on the benefits to positions spanning two otherwise unconnected contacts and thus advanced a more rigorous formulation of bridges. Although the analytic formulation of structural holes reflected spanning any two unconnected contacts, who could belong to the same or two different network communities (Burt 1992: 54-56), the theoretical premise of the argument strongly relied on the role of bridging ties across communities of otherwise unconnected contacts. Specifically, Burt (1992: 20, 28) stated that "redundancy is unlikely, indicating a structural hole, between total strangers in distant groups" and that "nonredundant ties are your bridges to other clusters." Finally, the notion of "range" focused on bridging as crossing domains of functional expertise rather than purely structural boundaries (Reagans and McEvily 2003).

A unifying feature of these perspectives is the common focus on the fundamental mechanisms underlying the benefits of bridging ties. More specifically, resources, knowledge, and information are more heterogeneous between rather than within network communities. By linking actors to different communities, bridging ties can therefore provide access to and control over diverse resources (see e.g., Burt 1992: 25-34; Granovetter 1983: 202, 228; Granovetter 1973: 1362, 1364-1365; Reagans et al. 2004: 105)4. Building on this antecedent theoretical platform, our paper contributes by offering a more precise alignment between the conceptual and empirical formulation of bridging ties, where bridges ties are theorized and modeled as ties that interconnect residents of distinct network communities, rather than simply ties between two otherwise unconnected actors.

\footnotetext{
${ }^{4}$ While all three streams emphasize the benefits of access to diverse information through bridging ties, they vary in the degree to which they emphasize the benefits of control over such information. For example, while Granovetter (1973: 1369-1371) acknowledged the role of "manipulation" in networks rich in bridging ties, Burt (1992: 30-34) accentuated the role of control benefits incurring to actors who span structural holes. Because identifying the unique role of the two mechanisms can pose a challenge even in experimental settings (Burt 2008; Reagans and Zuckerman 2008), this paper is based on the theoretical premise that both access to and control over diverse information are likely to underlie the benefits of bridging ties.
} 
It is essential to note that while research on the determinants of bridging ties has been virtually nonexistent in both the individual and corporate contexts, two recent lines of inquiry emerge as particularly relevant for our study. First some scholars have examined the antecedents of structural holes, or spanning otherwise unconnected actors, in intergroup settings and highlighted the role of social structure as a precursor for these positions (Zaheer and Soda 2009). Our focus here is on the determinants of bridging ties which reflect actors' efforts to span distinct communities of social structure (rather than simply unconnected actors. Structural holes, on the other hand, may occur as result of a tie dissolving between the actors' alters rather than as a result of the of actor's actions in response to the constraints and opportunities of social structure. The emphasis of this study, therefore, extends to the role of structural context in shaping actors' incentives and opportunities for action. Furthermore, by focusing on the determinants of inter-community ties - which are likely to have profound implications for the connectedness of global social systems - this study complements prior research by contributing to the investigations of the emergence and evolution of complex social systems.

Second, some recent work has traced the formation of bridging ties to the dynamics of market stratification. Specifically, scholars have emphasized the role of structural homophily, whereby partners with high centrality can gravitate to each other in bridging relationships (Rosenkopf and Padula 2008), and to insurgent partnering by peripheral firms and control partnering by dominant firms (Baum et al. 2003). This study contributes to and extends this work by suggesting that - in addition to the sustainability and change in the market's prominence order - the time-variant incentives of value creation and value distribution from bridging, as well as the opportunity structure for bridging for a given firm can critically shape the formation of bridging ties by that firm. In doing so, this study thus helps crystallize our understanding of how both proximate and global network structures can serve as dynamic determinants of extended contact in networks.

\section{Social Structure as an Enabler and Constraint of Action}

Understanding the role of social structure as an enabler and constraint of micro-level action occupies an important place in sociology and organization theory (e.g., Burt 1982; Coleman 1990; Rosenkopf and Padula 2008; Zaheer and Soda 2009). This placement is explained by the fact that the focus on the enabling and constraining role of social structure intermediates the atomistic theories of action, where actors' actions are presumed to be either exogenous or inherent to their dispositional characteristics, and the theories that view 
actors' behaviors as universally explained by the normative pressures of the social context (Granovetter 1985). The socio-structural lens is thus unique in that it conditions actors' behaviors on the particular properties of the surrounding social context, thereby allowing for the impact of social structure, which is yet measured and customized.

Applying the socio-structural lens to explain the determinants of bridging ties is valuable for two reasons. First, the value derived from bridging ties is contingent to a large degree on the participation of other actors, in terms of both translating novel insights into commercial applications and distributing the value of the concomitant production (Burt 2005; Fernandez-Mateo 2007). By capturing the patterns of interdependence in social systems (Cook 1977; Gulati and Sytch 2007; Ryall and Sorenson 2007), network structures can therefore offer a useful analytical lens to evaluate the value-creation and value-distribution incentives of forming new bridging ties. Second, the formation of bridging ties is a type of structural action, and the opportunity space for such action is conditioned to a large extent by the topological features of the surrounding social system. Thus, applying the network lens toward understanding the determinants of bridging ties is likely to generate valuable insights into both the incentives and the opportunities for entering into bridging ties.

\section{Proximate Network Structures and Firms' Incentives to Enter into Bridging Ties}

Incentives for bridging are likely to be a critical factor in determining the likelihood that firms will enter into bridging ties. Proximate search and homophilous attachment are strong forces that induce firms to stay within their familiar neighborhoods and form local (within-community) network ties (Ahuja et al. 2009; Powell et al. 2005; Shipilov and Li 2011). To break this cycle, firms need substantial incentives. In systems of interdependent exchange relationships, proximate network structures - defined by a firm's and its partners' direct connections - frequently embody patterns of interdependence (Reagans and Zuckerman 2008; Ryall and Sorenson 2007). The configuration and dynamics of these structures can thus affect how value is created and distributed for firms that enter into bridging relationships, thus enabling or constraining the formation of bridging ties.

Value-Creation Incentives 
Prior research has explored the idea that firms may create substantially different value from bridging ties. A seminal treatment in this respect is Burt's (2005) synthesis of structural holes and closure arguments. It suggests that while bridging ties provide access to diverse information, it is local ties or network communities that allow firms to use this information productively and efficiently (Baum et al. 2010; Burt 2005: 164; Reagans and Zuckerman 2001). Below we elaborate on this idea, demonstrating that network positions that combine bridging and local ties - sometimes described as "hybrid" network positions (Baum et al. 2010) - can enable firms to create superior value from entering into new bridging ties.

The importance of having multiple bridging ties rests on conceptualizing innovation as the process of recombining existing inputs (Schumpeter 1934). Subsequent studies have supported this notion by emphasizing the recombination of knowledge and resources across organizational boundaries (e.g., Hargadon and Sutton 1997; Rogers 2003). Recombination is particularly beneficial when it involves multiple heterogeneous inputs. The innovative success of Edison's laboratory, for instance, has been linked to its connections with multiple industries (DiMaggio 1992). A study of the product design firm IDEO similarly revealed that the links engineers forged with diverse industries exposed the firm to a broad range of technologies and positioned it to produce novel combinations of ideas in mechanical engineering and industrial design (Hargadon and Sutton 1997). In a structural context, where knowledge and information are more heterogeneous across network communities than within them, multiple bridging ties can provide the firm with salient advantages for knowledge recombination and thus offer a greater promise of value creation through entering into new bridging ties.

Existing bridging ties can increase the value-creation incentives from forming new bridging ties for several reasons. First, when combining inputs from a newly formed bridging tie with those from a firm's existing bridges, the firm can explore multiple permutations of knowledge and be positioned to produce a greater number of innovations. Furthermore, because the value of knowledge recombinations can differ, the opportunity to choose among multiple recombinant products can potentially allow the firm to obtain greater returns on innovation. Second, by incorporating multiple diverse inputs into recombinant products, the firm can strive for novel, complex, and less imitable recombinations. The reduced imitability of a complex innovation may in turn prolong the life cycle of the product in a competitive environment and extend the time through which the product creates value. Finally, by scanning a wider industrial space through existing bridges, the firm can detect a 
wider spectrum of commercially viable applications for its innovations (Hargadon and Sutton 1997). Thus, existing bridges can offer both benefits of recombinant innovation and the advantages of locating and exploiting new market opportunities.

The value-creation incentives offered by existing bridging ties, however, are less likely to materialize without an existing structure of local, or within-community, ties. While existing bridging ties offer greater potential for value creation when combined with new bridging ties, there are several reasons why existing local ties can enable firms to fully realize this potential. First, through strong reputational mechanisms and trust that characterizes closed networks, local ties may offer the potential for cost savings and greater innovative productivity. This is because in local partnerships, where trust is an effective and cost-efficient substitute for formal governance, firms need to invest less capital, effort, and time in establishing formal monitoring mechanisms (Arrow 1974; Bradach and Eccles 1989; Lincoln and Gerlach 2004). The strong reputational context characterizing closed networks is likely to further deter self-seeking advances, thus minimizing productivity losses (Greif 1989). Knowing that information about the quality of participation in joint efforts will diffuse quickly, some partners may also boost their collaborative efforts in order to secure future collaborations.

Second, closed networks can offer superior coordination mechanisms because their multiple redundant pathways create shorter distances between actors and thus facilitate faster and more reliable information flows (Baker and Faulkner 1993; Obsfeld 2005). This is particularly critical for complex tasks that involve recombining multiple, heterogeneous inputs. Third, because they represent strong and redundant connections, local ties generally result in better knowledge of the resources and skills among participating firms, thereby providing opportunities for these firms to efficiently collaborate for specific tasks (cf. Porac et al. 1995; Wegner 1986). In sum, while existing bridging ties can offer a fertile base for value creation by utilizing the inputs of newly formed bridging ties, existing local ties can enable that value to be captured in a less costly, more coordinated, and more efficient manner. The expectations of superior value creation through bridging ties and the concomitant valuecreation incentives for bridging are thus particularly likely to be noted for those firms that have the capacity to complement newly formed bridging ties with an existing structure of multiple bridging ties as well as multiple local ties. 
Note that this logic does not require the firm's agents to be aware of the exact patterns of network connectivity in the surrounding social space. Instead, existing bridging relationships are likely to equip the firm with a technological base diverse enough to recognize the value of knowledge recombination and seek further recombinations through new bridging ties. Whereas others might see a distant and unrelated knowledge input, the firm with an existing structure of bridging relationships will thus be more likely to spot opportunities for recombinant innovation. For example, the early bridging partnership between Intel and Palm (the manufacturer of one of the first personal digital assistants, or PDA's) to integrate Palm's operating system into Intel's microprocessor technology allowed Intel to see value in further developing embedded systems and virtual platforms. The idea was later extended to allow multiple operating systems to share one computing platform and thus integrate an entire spectrum of home devices, including PCs, tablets, energy management, security, televisions, and phones.

Similarly, existing local ties do not need to be recognized by the firms' agents as a structural property. Instead, having local partners and a history of collaborations with them may simply establish confidence in the returns of complex technological endeavors realized through bridging ties (which might require managing the interdependencies of diverse inputs), or from effectively delivering resultant products to customers. For example, many innovative products in the computer industry entail selling solutions or combinations of products and services (Bresnahan and Greenstein 1999). An established local distribution network may offer greater potential for the firm to realize value from a new recombinant product by quickly delivering that product to customers through a trusted distribution channel or by effectively coordinating across multiple distribution channels (Shepherd and Ahmed 2000). The latter is particularly important because customers in the computer industry increasingly require more complex and integrated solutions, placing even higher demands on coordinated delivery (Davies et al. 2007). This discussion leads to our first hypothesis:

Hypothesis 1: There will be a positive effect of the interaction between a firm's existing local and bridging ties on the number of new bridging ties into which the firm will enter in a subsequent period.

\section{Value-Distribution Incentives}

In a system of interdependent exchange relationships, firms are often compelled to react when the patterns of interdependence change (Mizruchi 1989; Pfeffer and Salancik 1978; Thompson 1967). One salient 
aspect of interdependence relates to mutual dependence between the firms that enter into bridging ties and their local partners positioned within the same network community (e.g., Bidwell and Fernandez-Mateo 2007; Ryall and Sorenson 2007). In this symbiotic relationship, firms with at least some bridging ties (i.e., bridging firms) supply valuable and novel information collected from the larger network, while firms with exclusively local connections (i.e., local partners) use that information at a premium, helping to apply it to commercial applications through joint efforts.

Social exchange theory suggests that if either party attempts to alter the pattern of dependence in a relationship, the other party is likely to respond to offset any disadvantageous changes in dependence (Emerson 1962, 1964). As we will show below, dependence in our setting could emanate from parties' reliance on bridging ties and the informational and resource benefits these ties offer. According to social exchange theory, if one party attempts to change the pattern of dependence in the relationship between the bridging firm and its local partner by forming a new bridging tie, the other party is likely to respond by offsetting the increased dependence.

The benefits of bridging ties emerge in part from the constraints on local partners' autonomy. Because local partners must rely on the bridging firm to supply new information, they have to cede a certain degree of control and value generated in the relationship to the bridging firm (Burt 1992). Put differently, local partners become critically dependent on the bridging firm in obtaining new and diverse information which they cannot otherwise access. This pattern of dependence is the foundation of the value-distribution incentives underlying the formation of bridging ties. The value of unique insights channeled through bridging ties is particularly important in the dynamic and knowledge-intense industries, where firms' survival often rests on continuous innovation (Gulati et al. 2011; Rowley et al. 2000). In these contexts (the computer industry is a prime example), forming new bridging ties is likely to be especially destabilizing to the dependence status quo. However, should local partners attempt to restore their autonomy by bypassing the bridging firm and forging new bridging connections on their own, the bridging firm may try to regain its structural advantage by forming new bridging ties as well. The alternative of restoring dependence status quo by forming new local ties is less likely. A bridging firm's doing so would entail, at least to some degree, ceding its position of structural autonomy in the community. This could trigger a cascading effect of disadvantageous dependence changes throughout the firm's 
other relationships. Forming bridging ties instead preserves the firm's overall position of structural autonomy in the network community.

Local partners may react by taking similar steps if their exchange partners pursue the benefits of bridging. If their exchange counterparts pursue new bridging connections, local partners - which are already structurally disadvantaged - become even more impaired. This is because their reliance on current and aspiring bridging firms increases even further due to the greater incoming volume of new and more valuable information. On the other hand, bridging firms may rely less on local partners for recombinant knowledge: as the value of their informational advantage increases with the formation of new bridging ties, they become more desirable partners for other local partners. Given that greater asymmetries in dependence may translate into a more disadvantageous distribution of value in the exchange relationship (e.g., Aldrich 1979; Cook 1977; Lavie 2007), it is reasonable to expect that local firms may strive to regain their structural autonomy by seeking out other partners through new bridging ties. Forming new bridges could provide then local firms with alternative routes to information, thus making them less dependent on current bridging firms and potentially turning them into more desirable partners for other firms in the network.

The possibilities for restoring the dependence status quo through forming local ties with other bridging firms are likely to be limited. One limitation is the availability of bridging firms in the local firm's network community: interorganizational network communities are typically sparsely connected with one another with only a handful of firms holding these bridging connections. The second limitation is that restoring the dependence status quo through a new local tie to a bridging firm would require brokering across two bridging firms in the community or phasing one firm out in favor of a substitute. Both alternatives are difficult. Brokering across bridging firms is doubtful given numerous available local partners, many of which would already interlink the bridging firms in the tight network community. Similarly, substituting the bridging partner could impose additional search constraints in terms of finding a partner with a more acceptable dependence position and expecting that the pattern of dependence will remain unchanged.

While it is clear that firms may attempt to rectify disadvantageous changes in dependence by forming new bridging ties, the question arises as to what may explain the initial change in the dependence status quo. It is important to note that although the initial dependence configuration constitutes the baseline point for our 
discussion, it is quite likely that one or both parties in an exchange relationship may not be fully satisfied with the current terms of the exchange. Active bridging firms may desire to appropriate a greater share of value in the relationship, while local firms may strive for greater parity. In other words, unless we assume that the market is in an equilibrium and all parties are perfectly satisfied with their current terms of exchange, it is more realistic to view the market as a dynamic system of transactions in which changes in dependence patterns are frequent and ordinary (see e.g., Ahuja et al. 2011; Hayek 1945). Furthermore, these changes may not be localized but rather cascade through the system, where restoring the dependence status quo for one set of firms may result in disrupting it for others.

In sum, to offset disadvantageous changes in dependence, both bridging and local firms may form new bridging ties in response to similar actions by the actors on whom they rely for economic exchange. Note that this argument does not conceive of firms as "astute networkers" with superior abilities to monitor changes in the surrounding social structure. Rather, the pressure to restore the dependence status quo will come from the firms that face increasingly disadvantageous terms of exchange or loss-avoidance incentives, which result from their counterparts' power positions being improved by adding new bridging ties (see e.g., Lavie 2007). Thus, it appears that both incumbent bridging firms and their local partners may by induced by value-distribution incentives to form new bridging ties in response to similar actions by their exchange partners. Hence, we propose:

Hypothesis 2: The greater the number of bridging ties formed by firms on which the focal firm is dependent, the greater the number of new bridging ties into which the focal firm will enter in a subsequent period.

\section{Global Network Structure and Firms' Opportunity to Enter into Bridging Ties}

A firm's entering into bridging ties could be critically affected by the level of opportunity for doing so, which is inherent to the evolving global network structure for a firm at any given point in time. Our logic for this argument is based on Blau's fundamental theory of the structural context of opportunities (Blau 1977, 1994; Blau and Schwartz 1984; Rytina and Morgan 1982), which builds on the earlier work by Simmel (1955) on crosscutting social circles. This theory accepts that social actors tend to prefer partnering within groups to partnering across groups (cf. Li and Rowley 2002; McPherson et al. 2001) and focuses on how social relations emerge across groups. Its central claims are twofold. The first one is that the formation of social relations depends on the 
opportunities for contact. And, second, that the distribution of actors among social positions influences the likelihood of social relations by circumscribing, in part, the opportunities for contact.

These ideas are relevant for examining how firms enter into bridging relationships. Initial encounters are essential for any social relationships to develop. Some encounters are fortuitous: just as marriages can develop after individuals meet at a school event, interfirm partnerships sometimes result when managers and executives interact at professional conferences, cooperative technical organizations, trade associations, or on the golf course (e.g., Rosenkopf et al. 2001). ${ }^{5}$ The distribution of firms across network communities is what determines whether these encounters occur between firm agents from the same community or from different communities. The larger the pool of potentially available firms from other network communities (relative to the size of the focal firm's community), the greater is the (relative) structural opportunity for cross-community contact and, therefore, the greater is the likelihood of cross-community bridging relationships.

A bridging connection involves a link between firms occupying distinct structural neighborhoods or groups. Thus, a firm's opportunity to form a bridge is reflected in the number of available bridging partners: that is, firms residing in network communities different from the focal firm's and thus capable of forming a bridging tie. Following Blau, it is essential to look at how opportunities are distributed for encountering a bridging contact (i.e., a partner from a different network community) relative to encountering a local contact (i.e., a partner residing in the same network community). This opportunity space changes with the dynamics of the global network structure, such that a greater relative opportunity for encountering a bridging contact is likely to exert a positive effect on a firm's propensity to enter into bridging ties.

More importantly, the effect of opportunity on the formation of bridging ties is likely to be independent of the value-creation and value-distribution incentives for bridging. This claim rests on the expectation that, at least in some cases, certain collaboration dynamics may make the benefits offered by bridging relationships not perfectly distinguishable from those offered by local ties. On the one hand, through personal interactions with a bridging partner's organizational agents, a focal firm's agents could become reassured of a potential for secure

\footnotetext{
5 An early study of opportunities for contact was reported by Festinger, Schachter, and Back (1950), who investigated how friendships formed among students in two-story MIT dormitories. In general, students were more likely to become friends with someone from their own floor. Cross-floor friendships, however, were more likely with students occupying rooms at the foot of the stairs leading to the second floor. These students were more likely to randomly bump into second-floor residents, which led to casual conversations and, later, friendships.
} 
and reliable cooperation with the bridging partner. In this case, creating a bridge would be very much akin to forming a local connection. On the other hand, the ability of a local partner to influence the firm's agents through embedded network ties (Rogers 2003) could increase the perceived value of locally availably knowledge, thereby turning it into an acceptable input for recombinant search. Taken together, these factors could lead to some ambiguities around the perceived value of bridging versus local ties. Because of these ambiguities, the firm's opportunity structure for bridging and the resulting chance interactions with bridging contacts is likely to affect the firm's entering into bridging ties independently of the incentives for value creation and distribution created by the firm's proximate network structure.

In advancing this prediction, it is important to consider that in an interorganizational network, a firm's network community is typically rather small relative to the larger network; therefore, every firm is likely to have substantial de facto structural opportunities for reaching out to firms in other network communities. More importantly, identifying the effect of structural opportunity relies on capturing changes in the global network structure. Without immediate constraints on the availability of partners from other communities, it is precisely the mechanism of chance encounters that would produce an increase in a firm's newly formed bridging ties in proportion to the increase in the structural opportunities for contact across network communities.

More broadly, this effect also pits the role of global network structure against firm-specific characteristics and the incentives for bridging tie formation. If the time-variant incentives and fixed firm-level characteristics dominate the selection process, then structural opportunity may simply have a null effect on the formation of bridging ties. In the most extreme case, one could envision the opposite effect, where a greater number of parties from other network communities could increase the salience of local within-community categories and categorical faultlines across communities. This dynamic could thus stimulate local (withincommunity) rather than bridging (cross-community) partnering. The logic of structural opportunity for extended contact and the mechanism of chance encounters, in contrast, suggest that firms with greater relative opportunities for encountering a bridging contact will increase the number of bridging ties formed. Thus:

Hypothesis 3: The greater the number of available bridging partners (relative to the number of available local partners), the greater the number of new bridging ties into which the firm will enter in a subsequent period.

\section{Data and Methods}


We use partnership data from the Securities Data Company (SDC) Platinum database provided by Thomson Financial (e.g., Anand and Khanna 2000; Casciaro 2003; Rosenkopf et al. 2001) to track the evolving network of interorganizational partnerships in the global computer industry from 1991 to 2005. Networks of interorganizational partnerships are considered to offer a particularly rich domain to study the embeddedness of economic action and have been analyzed extensively in both organizational theory and sociology (e.g., Ahuja 2000a; Gulati and Gargiulo 1999; Kogut and Walker 2001; Powell et al. 2005; Uzzi 1996). In these networks, the firms are included as nodes and the partnerships are mapped as undirected network ties interconnecting pairs of firms.

To differentiate between bridging and local ties, one needs to thoroughly understand the network's community structure, which, in turn, requires a fully enumerated industry network. Given our focus on the global computer industry, we limited our sample to partnerships where (i) at least one of the partners was in the computer industry based on its primary four-digit SIC code, and (ii) the main partnership activity fell within the computer industry. This meant that some companies could enter the network from other industries, provided they formed an alliance with at least one company in computers and that the alliance itself was assigned an SIC code within the computer industry. These sampling criteria led us to consider 5,910 interfirm partnerships and 7,962 unique participant firms over the 15 -year period. The network size changed substantially over that period, growing from 217 firms in late 1991 to its maximum of 6,221 firms in early 2004. When reconstructing this network, we followed extant research regarding the choice of alliance duration and network enumeration.

Because the dates of alliance termination are not usually reported, we followed prior research in using a five-year window for alliance duration (e.g., Gulati and Gargiulo 1999; Kogut 1988; Stuart 1998). ${ }^{6}$ To promote high levels of granularity in analyzing network evolution, we traced alliance formation on a semi-annual basis. ${ }^{7}$

\section{Dependent Variable}

Our dependent variable is the total count of new bridging ties formed by the focal firm at time $t+1$. In contrast to a local tie, which connects firms within a network community, a bridging tie runs between network

\footnotetext{
${ }^{6}$ For 65 partnerships, we could establish precise termination dates based on SDC data. We determined that their average tenure was close to five years, which further supported our choice of a five-year moving window.

${ }^{7}$ For multilateral partnerships, we followed a standard procedure by treating them as completely connected graphs and incorporating them into the network as sets of dyadic links (for a similar treatment see Gulati 1995; Stuart 1998). Given the paucity of multilateral partnerships (the number of firms in a typical partnership was around two), this empirical choice had no effect on the key network properties of interest in this study.
} 
communities (cf. Gould and Fernandez, 1989). Given the difficulties of identifying which firm initiated a specific interorganizational partnership, this research design captures the variance attributed to the focal firm's characteristics (for a similar approach, see Gulati 1999; Lavie and Rosenkopf 2006; Powell 1996). Considering the unexplained variance on the other side of the dyad, this design offers a more conservative test for the theory advanced in this study.

Distinguishing bridging from local ties required us to identify the community structure of the evolving network of firms. Like other social networks, the evolving network of firms consisted of many disconnected components in each period (Wasserman and Faust 1994). While smaller, peripheral components could be viewed as consisting of local ties only (because their limited size precluded the existence of multiple cohesive groups of firms), the biggest connected, or main, component in our data carried a larger, more complex inner structure. It thus posed a greater challenge to isolate its communities and distinguish bridging ties from local ties. ${ }^{8}$

Identifying network communities has received significant attention in both sociology (e.g., Davis 1967) and statistical physics (e.g., Newman 2004). The central idea entails partitioning the network into groups of nodes in a way that the density of ties within groups is higher than between groups. Earlier approaches to network partitioning typically relied on some variation of hierarchical clustering (Wasserman and Faust 1994). This method is useful for certain types of smaller networks in which the "natural" dividing lines between communities are implied by actor attributes, suggesting some a priori knowledge about the actors' group affiliations. It is, however, less appropriate in partitioning large graphs that can be characterized by less evident cluster structures. In these situations, the main disadvantage of hierarchical clustering is that it requires arbitrary specifications with respect to how many communities are to be extracted or how big they are on average.

Given no prior knowledge about how our network is segmented into network communities on the basis of firm attributes, we relied on a community-detection algorithm with a statistical goodness-of-split index (modularity) proposed by Girvan and Newman (2002). This algorithm differentiates between ties with low betweeness-centrality scores, which are more likely to run within communities, and ties with high betweennesscentrality scores, which are more likely to bridge communities (Girvan and Newman 2002). Ties with high

\footnotetext{
${ }^{8}$ Clearly representing the core of the evolving network, the biggest component in our data increased substantially in size, from 17 firms in 1991 to 1,822 firms in 2004. During that period, all other components ranked significantly lower. In fact, we established that more than $90 \%$ of them were single, isolated dyads.
} 
betweenness-centrality scores are likely to indicate network bottlenecks because anything that travels through them, from one community to another, must eventually travel over one of such bridges. This technique is therefore particularly appropriate for isolating communities in a network and identifying the bridging ties that span them. Modularity, in turn, helps evaluate the quality of a given division into communities by comparing it to a fully random division. ${ }^{9}$ A recent study on the performance of clustering algorithms in networks with known community structures (e.g., Zachary's (1977) famous karate club network) confirmed the robustness of the modularity-based approach (Danon et al. 2005).10

Values of modularity higher than 0.3 indicate a good division of the network (Newman 2004). We thus estimated modularity for all 29 semi-annual networks from 1991 to 2005 to verify the robustness of our network partitioning. The average modularity of 0.65 and the lowest modularity of 0.32 (registered in 1996) confirmed a robust partitioning of the network across all time periods. The divisions resulted in a variable number of communities, ranging from 3 in the years 1992-1994 to 65 in 2004. The average number of firms per community varied between 3.4 in 1991 and 34.19 in $2005 .{ }^{11}$ Based on these results, we obtained the counts of bridging ties in each network, which ranged from just 2 ties over 1992-1994 to 391 ties in 2004. On average, bridging ties constituted $13 \%$ of all network ties in the main component, which indicates a highly segmented network with a

\footnotetext{
${ }^{9}$ Following prior research (e.g., Porter et al. 2007), we used the modularity index to assess analytically the degree to which our community partitioning is accurate. Such a partitioning is achieved if the number of ties identified within communities is significantly greater than the number of ties across communities. The key advantage of the modularity-based approach is that it offers a robust baseline for comparing the distribution of ties obtained for the observed network with the corresponding distribution for a fully random network, in which ties are placed without any regard for community structure (such as the Erdos-Renyi network, in which any two actors are simply connected with a certain fixed probability). Because the random network has no discernible community structure, its modularity is very low (typically just above zero). A low-quality partitioning thus results in a low modularity index that is not substantially different from that baseline random value. This indicates either that the network has a weak (i.e., almost random) community structure, or that the partitioning can be improved to obtain a higher modularity score. A high-quality partitioning on a robust network structure, by contrast, produces a significantly greater modularity index, which normally lies between 0.3 and 0.7 (Newman, 2006). Theoretically, modularity can reach 1.0 , but values above 0.7 are rare in real networks. For a formal definition and the mathematical specification of modularity, see Girvan and Newman (2002).

10 One could consider an alternative way to partition the system based on purely technological considerations. Given the empirical context, this method is less effective for two reasons. First, many computer companies are engaged in multiple lines of business (e.g., HP manufactures printers, servers, and laptops); therefore, identifying the technological communities based on company profiles would be complicated. Second, research indicates that beyond the technological parameters driving partnership ties, such as the similarity and complementarity of firms' resource portfolios (e.g., Mowery et al. 1998; Stuart 1998; Wang and Zajac 2007), there are strong sociostructural imperatives that determine how firms collaborate. These imperatives include, for example, the structure of opportunity in the social system, the ability to solicit referrals and locate credible partners, and status considerations (e.g., Chung et al. 2000; Gulati 1995; Podolny 1994). Studies have therefore emphasized that these factors eventually become paramount in determining how technology communities emerge and evolve (Owen-Smith and Powell 2004; Saxenian 1994). Thus, focusing purely on a technological baseline for partitioning a network is not only empirically challenging, but could also marginalize the role of social forces in shaping the actual patterns of collaboration, knowledge flows, and the eventual structure of the firm and knowledge communities.

11 Because these results rely to some degree on the mechanics of our partitioning procedure, we also verified them using alternative partitioning methods. Specifically, we used a more recent method proposed by Guimera et al. (2004), which is based on simulated annealing. This approach is more computationally intensive, but produces accurate results on smaller- to medium-sized networks. Community partitioning produced by this algorithm was consistent with that identified by the Girvan-Newman (2002) algorithm. See also Danon et al. (2005) for detailed comparisons of available partitioning methods.
} 
strong community structure. ${ }^{12}$ Subsequently, we used this information to derive the counts of newly formed bridging ties for each firm in a given time period in order to construct our dependent variable, New bridging ties.

To further test the robustness of our network partitioning, we investigated whether network communities tend to comprise more homogeneous firms than could be expected by chance. Indeed, the principle of homophilous interaction - suggesting that actors tend to seek similar others in local partnering (Ahuja et al. 2009; McPherson et al. 2001) - serves as one of the foundations for the fact that knowledge and other resources tend to be more homogeneous within network communities than between them. Using firms' national origin and 2-digit primary SIC classification as two of the most salient categorical attributes, we found that the composition of communities was far more homogeneous on these dimensions than what one would expect by random chance only. Coupled with the high robustness of the partitioning results, this additional finding confirms that our community structure mapped onto distinct communities of firms within the computer industry. These communities are likely to represent not only cohesive social groups of firms, but also homogeneous pockets of information, knowledge, and other key resources. ${ }^{13}$

It would be difficult to undertake a detailed content analysis of all partnerships in the network due to their sheer volume and the differences in companies' reporting standards. We observed, however, that many bridging partnerships indeed spanned different technological domains to generate major product innovations or new technological solutions. For example, the 2001 partnership between Palm and Intel was created to integrate Palm's operating system into Intel chips. Similarly, AOL and Hewlett-Packard partnered in 1999 to offer AOL's customers greater online printing capabilities. By contrast, we found that local partnerships frequently concentrated on the utilization and enhancement of existing technologies. Examples of such local deals included

\footnotetext{
12 In addition to bridging ties running between existing communities in the main component, we also registered new bridges that resulted from connections between the main component and peripheral communities attaching to the main component at time $t+1$.

${ }^{13}$ Note that our measure of bridging captures bridges that span distinct network communities (Gould and Fernandez 1989) as opposed to all unconnected contacts, including those in the same community. This measure is effective in matching our research question to the empirical context. First, the logic of bridging ties addresses the bridging firm's advantage related to accessing heterogeneous pools of knowledge. It is more likely that partnerships with firms from entirely different network communities will provide the firm with access to a diverse pool of knowledge, rather than those with partners that are unconnected to one or more of its current partners (all of which could come from the firm's own structural neighborhood). This distinction becomes especially relevant in the context of the computer industry, where distinct and sizable groups of firms cluster around ostensibly different, but internally homogeneous pools of knowledge and which use that knowledge to develop distinct component technologies. Counting the bridging ties between the resultant cohesive network communities, therefore, allows us to capture the fundamental informational qualities of the partnership network observed in this setting.
} 
the 2001 partnership between Minolta and Fujitsu to manufacture, develop, and market high-speed color laser printers and the 2004 alliance between IBM and Lenovo to offer joint PC sales, services, and financing.

In addition, we measured the relative distance between the portfolios of partners for firms in local versus bridging dyads. Specifically, we compared the distribution of the firms' partners across different industry segments (e.g. hardware, operating systems, business services, etc.) using the first two digits of the partners' primary SIC codes. Our expectation was that firms in bridging dyads would show a greater relative difference in their portfolios of partners than firms in local dyads. This would confirm that firms in bridging ties are more likely to draw on a more distinct technological base in the industry than firms in local ties. Using the cosine distance formula, we found that the mean distance between the partner portfolios of firms in bridging dyads was 0.37. The corresponding mean distance for firms in local dyads was 0.18 (this difference in means was statistically significant at $p<0.001)$. This result confirms our expectation that bridging partners are more likely to draw on a distinct technological base in the industry compared to local partners.

\section{Independent and Control Variables}

We operationalized the firm's value-creation incentives to form new bridging ties using the interaction between the counts of bridging and local ties that the firm currently maintains (Current bridging ties $x$ Current local ties). Both counts were additionally centered around the mean to reduce multicollinearity and logged to reduce distributional skewness (e.g., Haunschild and Beckman 1998: 824; Jensen 2003: 483; Shane 1996: 224). In this and subsequent cases that involved log-transformations, we verified that transforming the variable results in a significantly improved model fit. Formally, this variable is specified as $\log \left(d_{i}^{\beta}-d_{m}^{\beta}\right) \times \log \left(d_{i}^{\lambda}-d_{m}^{\lambda}\right)$, where $d_{i}^{\beta}$ is number of firm's bridging ties at time $t, d_{i}^{\lambda}$ is the number of the firm's local ties at $t$, and $d_{m}^{\beta}$ and $d_{m}^{\lambda}$ are respective mean values of bridging and local ties computed at the level of the entire sample. ${ }^{14}$ Next, we captured

\footnotetext{
${ }^{14}$ An alternative conceptualization of the value-creation incentives would rely on the ratio of bridging to local ties. This approach is less appropriate for two reasons. First, the ratio approach would place strict conditions in that all local and bridging ties would be considered substitutable in their respective categories. That is, a dissolution of any single bridging tie at $t-1$ would be considered as rectified (for valuecreation purposes) by forming any single new bridging relationship. Both bridging and local relationships can vary in their intensity and transmission capacity, and the level of attention and resources organizations devote to them, hence providing varying contributions to value creation. Second, this approach would require assuming that the ratio itself oscillates around some anchoring value over time, and that it is the deviations from that value that would trigger the formation of new bridging ties. Both the changing carrying capacity of firms to maintain new ties (which could well be due to unobservable factors) and the heterogeneity of these ties themselves, however, are likely to produce a high degree of variance in the "preferred" or "optimal" ratio of bridging to local ties over time. Assuming that the ratio has a fixed anchor value, therefore, would result in a misspecified model. The interaction-based approach relaxes both of these assumptions. Further, this approach is more realistic in that even a stable ratio of bridging to local ties can stimulate forming additional bridging ties due
} 
the value-distribution incentives of a firm at time $t+1$ using the log-transformed count of new bridging ties formed by the firm's partners at time $t$ (Bridging ties by dependent firms). The measure can be specified as $\log \left(\sum_{j} d_{j}^{\beta}\right)$, where $\sum_{j} d_{j}^{\beta}$ is the total number of new bridging ties formed by the firm $j$ s partners at time $t .15$ Finally, we measured the firm's opportunity to form bridging ties (Potential bridging partners) using the logged ratio of potential partners outside the firm's community to potential partners inside the firm's community (cf. Blau 1977). This entailed taking, for each firm, the ratio of firms outside the firm's network community (excluding firms to which the focal firm was already connected at time $t$ through a bridging tie) to firms inside the firm's network community (excluding firms to which the focal firm was connected at $t$ through a local tie). To ensure that we did not include actors who lacked the necessary conditions for tie formation, we counted only firms that actually formed at least one new network tie at time $t+1$. Formally: $\log \left\{\left[\left(N-C_{i}\right)^{\prime}-d_{i}^{\beta}\right] /\left(C_{i}^{\prime}-d_{i}^{\lambda}\right)\right\}$, where $\left(N-C_{i}\right)^{\prime}$ is the total count of firms outside the focal firm's network community in $t$ that formed at least one new tie in $t+1$, and $d_{i}^{\beta}$ is the number of $\imath$ s existing bridging partners in $t . C_{i}^{\prime}$ is the total count of firms in $i$ s network community that formed at least one new local tie in $t+1$ and $d_{i}^{\lambda}$ is number of $\imath$ s existing local partners in t. The opportunity variable thus reflects the complex dynamics of the evolving global network structure, captured in the changing size of the network; the relative distribution of firms across the focal firm's network community versus other communities; and the comparative tendency of firms to enter into partnerships. ${ }^{16}$

In each model, we controlled for firm size (Sales and Headcount) and current financial performance (Net income), all logged to mitigate skewness. An important factor that can impact a firm's propensity to form new bridging ties is its social status (Jensen 2003). We controlled for status with the commonly-used measure of Eigenvector centrality (Bonacich 1972). To account for unobserved heterogeneity, we also tracked each firm's Prior bridging experience, using the logged count of partnership ties the firm created prior to $t-5$. To control for the firm's

to either (i) the value-creation incentives of additional recombination or (ii) loss-avoidance incentives that are related to the decay of knowledge in existing ties.

${ }^{15} \mathrm{It}$ is essential to notice that interorganizational partnership ties typically entail non-trivial levels of dependence: they involve significant resource transfers (Gomes-Casseres et al. 2006), relationship-specific investments (Uzzi 1997), customized governance and coordination mechanisms (Vanneste and Puranam 2010), and carry substantial switching costs (Gulati et al. 2008). That said, one limitation of this approach to dependence is that we are unable to differentiate among various magnitudes of dependence, which can be associated with the exact levels of criticality and substitutability of the benefits offered by a given partner.

16 While the size of the network and the number of clusters in the network increase throughout the study period, these dynamics alone account for just slightly more than one-third of the variation in the opportunity measure. Our statistical model controlled for the period fixed effects, thus absorbing this variance. 
current network position, we incorporated the variables of the firm's Current local ties and Current bridging ties, reflecting the logged counts of the firm's existing within-community and between-community ties, respectively.

We used binary variables to denote a firm that was present in the network in past periods as opposed to a new entrant at time $t$ (Incumbent firm) ${ }^{17}$ Because the rate of bridging tie formation varied in the computer industry over 1990-2005 (Gulati et al. 2011), we accounted for these industry-level dynamics by controlling for the Period fixed effects. In additional analyses, we decomposed the period effects into pre- and post-2000 effects. Further, in alternative model specifications, we controlled for the time-variant aggregate propensity of firms to enter into bridging ties. This, however, did not change the pattern of results reported here. Finally, a firm's propensity to enter into bridging ties is likely to be driven by a set of unobservable firm-specific characteristics, at least some of which can be assumed to be correlated with network incentives and structural opportunities for bridging. To isolate the effects of the evolving local and global network structures, we accounted for firm-level unobservable heterogeneity by using a fixed-effects estimation procedure, which effectively controlled for all firm-level, time-invariant covariates, such as industry affiliation, geographical position, and national origin, among others. Using firm-level fixed effects also helped us account for the possibility that some firms could be inherently more exploration-focused than others; work with original equipment manufacturers as opposed to building their own brand; or be more diversified than other firms.

A key concern in modeling network data is the nonindependence of observations in the network context. To address this issue, we relied on a two-pronged approach in our statistical modeling. First, we clustered standard errors at the firm level, which minimized the risk of a downward estimation of standard errors (Rogers 1993). Second, consistent with prior research (e.g., Baum et al. 2005; Doreian 1989; Marsden and Friedkin 1993), we modeled Network autocorrelation as a network influence process of the form $y_{t+1}=\varrho W_{i j, t} y_{j, t}+x \beta$ $+\varepsilon$, where $W_{i j, t}$ is the industrial similarity between the focal firm $i$ and all other firms $j$ in the network at time $t$, and $y_{j, t}$ is the corresponding lagged dependent action of $j$ (e.g., the total count of new bridging ties created by $j$ at time $t$. We specified $W_{i j, t}$ as 1 if firms $i$ and $j$ belonged to the same business group according to the first two

${ }_{17}$ In additional tests, we also controlled for firms' technological endowments using the logged number of patents for each firm. Echoing the findings of prior research, which demonstrated the role of technological resource endowments in determining the propensity of firms to enter into interfirm partnerships (Ahuja, 2000b), and consistent with the notion that more innovative companies are more likely to pursue diverse knowledge through bridging ties, this variable had a significant positive impact on the likelihood of bridging tie formation while leaving other effects intact. Because patent data are available in a systematic format only up to 2002 (Hall et al. 2001), using these data leads to a truncation of our observation period. We do not, therefore, include the patent control in the reported models. 
digits of their SIC codes and 0 otherwise. Analyzing the empirical context confirmed that the two-digit business groups can certainly differentiate firms in the computer industry, and hence offer a good proxy for interfirm similarity and the related network influence. ${ }^{18}$

\section{Analysis}

Our dependent variable - the number of new bridging ties a firm forms in a given time period - is a count variable that can be analyzed using a family of count regression models (e.g., Cameron and Trivedi 1998). As in many other empirical settings (e.g., Hausman et al. 1984; Rothaermel 2001; Schilling and Phelps 2007), this variable displayed substantial overdispersion. Under these conditions, the negative binomial regression, which relaxes the assumption of equality between the mean and the variance, is a preferred technique (Hilbe 2007).

The fixed-effects estimator for maximum likelihood models is conditioned on the sum of the count for each firm; therefore, firms that had not formed a single bridging tie over the observation period were treated as not contributing to the likelihood function and were thus dropped from the estimation. After eliminating the observations with missing Compustat data, we retained 1,926 observations related to 138 firms that had formed at least one bridging tie during the entire observation period. An alternative way to factor out firm-specific heterogeneity that would retain the entire sample is random-effects modeling. The Hausman (1978) test, however, rejected the random-effects model $(p<0.001)$.

To ensure that our results were not affected by sample truncation, we standardized the dependent variable, transforming it into a continuous outcome and applied a fixed-effects OLS estimator. Unlike maximumlikelihood models, where the fixed-effects estimator eliminates all firms with a constant zero outcome over the observation period, the OLS fixed-effects estimator uses the entire sample including firms that have never formed a bridging tie. Thus, in addition to reporting the results of the fixed-effects negative binomial estimation, we also present the full-sample, fixed-effects OLS results.

We also verified our results using the zero-inflated negative binomial model (Hilbe 2007). The zeroinflated negative binomial model proceeds in two steps. In the first stage, it distributes observations into two

\footnotetext{
${ }^{18}$ In a set of robustness tests, we additionally modeled network influence based on three alternative measures of similarity: (i) size similarity based on headcount; (ii) financial performance similarity based on return on assets; and (iii) technological similarity based on the distribution of firms' partners across the two-digit SIC groups. In all instances, the effect of the similarity measure on the dependent variable was weaker $(p<0.10)$ compared to the one reported here based on firms' industrial similarity. All other effects remained similar.
} 
latent groups having either zero or non-zero counts of bridging ties using a logit function. In the second stage, it estimates the count of bridging ties conditional on the first stage. Our results indicated that the negative binomial model predicted the count of new bridging ties just as accurately as the zero-inflated negative binomial model. The Vuong (1989) test similarly failed to favor the zero-inflated negative binomial model; moreover, the estimates produced by the zero-inflated negative binomial model were qualitatively similar to those of the negative binomial model. The results of these additional tests assured us that omitting the all-zero observations does not bias the negative binomial estimates.

While negative binomial estimation is effective in dealing with overdispersion, it could lead to biased estimates should the data suffer from autocorrelation or distributional misspecification. We therefore reestimated all models using a Poisson regression (which is unbiased in the face of these problems), with Wooldridge (1999) standard errors that are robust to overdispersion. As a final check, to account explicitly for possible autocorrelation, we estimated a set of first-order autoregressive GLS models. We observed no substantive differences with the reported pattern of results.

\section{Results}

Descriptive statistics and correlations among the control and independent variables are presented in Table 1. We observed generally low levels of bivariate correlations, suggesting that multicollinearity should not pose a serious statistical issue. However, since bivariate correlations are not entirely diagnostic of multicollinearity (or the lack thereof) for the overall estimation process, we also confirmed that the condition indices remained low and guaranteed sufficient statistical power (Belsey et al. 1980).

Models 1-9 in Table 2 report the results of our study. Among the control variables, eigenvector centrality has a negative effect on the formation of bridging ties. This could suggest that high-status organizations, which can secure preferential terms of exchange in other relationships, are less inclined to pursue bridging ties. Also, network incumbents are less prone to form new bridging ties. This result could be due to the study's period, which coincided with the early stages of the network evolution. At that time, the main component of the network grew consistently through the addition of new network communities. We also find that while a firm's current local ties have a positive effect on the formation of new bridging ties, its current bridging ties have a 
negative effect. While the positive effect of local ties may reflect the need to complement a closed position with bridging ties (e.g., Burt 2005), the negative effect of current bridging ties is a surprising result. ${ }^{19}$ More refined metrics of a firm's network position, such as those reflecting the count of bridges and their distribution across different network communities (Guimera and Amaral 2005), could shed further light on this effect.

In Models 2-4, we used conditional fixed-effects negative binomial estimation to predict the count of newly formed bridging ties for firms that had formed at least one bridging tie during the observation period. In Models 5-7, in turn, we used a fixed-effects OLS estimator on a standardized dependent variable. The OLS estimator retains firms that had not formed a single bridging tie during the observation period, thereby avoiding sample truncation. To investigate whether changes in incentives and opportunities for bridging could translate into firms' increased propensity to enter into bridging ties relative to local ties, in Models 3 and 6 we controlled for new local ties formed in period $t+1$. Further, Models 8 and 9 used the ratio of newly formed bridging ties to all newly formed ties as the dependent variable. Finally, because Models 2, 5, and 8 used Compustat data to control for a firm's headcount, sales, and net income, we had to drop all observations that lacked these data. Auxiliary analyses indicated that the financial data were not missing randomly with respect to the counts of bridging ties formed $(p<0.001$ for OLS; and $p<0.10$ for NB). To ensure robustness to non-random data omission, Models 4, 7, and 9 replicated models 2, 5, and 8 respectively, while preserving observations with missing financial data.

The results across all models consistently indicate that that firms' incentives and opportunities for bridging have positive and significant effects on the formation of new bridging ties, thus supporting Hypotheses 1, 2, and 3. Specifically, Hypothesis 1 predicted a positive joint effect of current local and current bridging ties (Current local ties $\times$ Current bridging ties) on new bridging ties. Increasing both current local ties and current bridging ties by one standard deviation from their mean values (i.e., from 6 to 14 for local ties and from 2 to 8 for bridges) thus results in a $42 \%$ greater predicted count of new bridging ties in Model 2. For an alternative

19 We ensured that this result was not driven by a statistical misspecification of the relationship. While we observed diminishing returns to bridging ties in a curvilinear specification, the inflection point was far outside the sample range and the general fit of the model worsened significantly. As a robustness check, we also experimented with various moving windows for counting bridging ties, going back to 1991. In addition, we used decay functions to see if this variable could capture the effects of experiential learning in bridging tie formation. The results across all these tests were similar to those reported here. Finally, we also ruled out the possibility that the estimated negative impact of current bridging ties could be driven by a ceiling effect on the dependent variable, such that firms could not move beyond a certain maximum number of bridging partnerships in a given point in time. Specifically, we estimated that even under (i) the strictest assumption of the absolute lowest ceiling of bridging opportunity in all time periods, and (ii) assuming that any firm could double the empirically observed maximum carrying capacity in forming partnerships and have all its ties formed as bridges, nearly three times more bridging ties would still be needed to reach the lowest ceiling. 
conceptualization of the value-creation incentives in period $t+1$, we re-estimated this effect after eliminating both local and bridging ties that would dissolve in period $t+1$. The results remained unchanged.

In additional analyses, we found that the counts of current local and current bridging ties operate differently when we consider the main effect and the interaction jointly. Specifically, adding current local ties increases the formation of new bridging ties at any level of current bridging ties. In contrast, adding current bridging ties while holding current local ties constant decreases the formation of new bridging ties unless we consider network positions that are extremely well endowed with local ties (i.e., three standard deviations above the mean in the negative binomial specification and two standard deviations above the mean in the OLS specification). One possible theoretical interpretation of this effect is that there is a difference in how current local ties and current bridging ties contribute to value creation through recombinant innovation. In our context, it could be that having more current bridging ties produces extremely high levels of recombinant complexity for value creation, thereby overwhelming the incentives for knowledge recombination. This recombinant complexity could have a negative impact on a firm's propensity to form new bridges unless the firm manages to mitigate this effect through a large network of current local ties. Such a large local network may help the firm develop a greater capacity for coordinated delivery, thereby mitigating the complexity constraints from existing bridges.

Hypothesis 2 focused on the role of a firm's value-distribution incentives to enter into new bridging ties as indicated by the changes in the firm's dependence status quo in the social system. The variable Bridging ties by dependent firms reflects value-distribution incentives for the firm to reinstitute the dependence status quo by forming new bridging ties. The effect of the variable is positive and significant, thus supporting Hypothesis 2. Following a one standard-deviation increase in the value-distribution incentives (reflecting two extra bridging ties formed by the firm's partners at time $t$ ), a typical firm in our data will thus register a $26 \%$ greater count of new bridges at $t+1$. As a robustness check, rather than counting the number of bridging ties formed by the firm's exchange partners, we used (i) the net change in the counts of bridging ties (controlling for decay) of the firms' partners, and (ii) the count of partners that formed at least one bridging tie. Both variables were highly correlated with the count of bridging ties formed by the firms' current exchange partners and produced similar results.

One challenge here is to isolate the changes in interfirm dependence landscape from simple mimicry, wherein a firm may blindly imitate others in forming new bridging ties. Other firms' goals in reaching out to new 
network neighborhoods may be ambiguous, new technologies that these neighborhoods offer may be poorly understood, and the overall environment is likely to be quite uncertain. Under these circumstances, some firms could simply mimic the partnership behaviors of other firms, yielding to the social proof of high-frequency acts rather than following their own idiosyncratic strategies (DiMaggio and Powell 1983). While this argument could potentially apply to situations in which a firm follows in the footsteps of its direct partners, it should also apply to its following other firms whose actions are directly observable (e.g., Haunschild and Miner 1997; Rao et al. 2001). In fact, the imitation argument carries more validity for non-partners, because it is reasonable to expect organizational agents to be better at understanding (or at least be more confident in ascribing) the rationale behind the formation of bridging ties by their direct partners and hence avoiding blind mimicry.

To check for possible imitation, we created two alternative variables that measured the number of firms to which the focal firm is not directly connected that formed new bridging ties at $t$ from (i) the focal firm's network community and (ii) the network community to which the focal firm's local community had the most bridging connections at $t$. Both of these cases excluded the firm's current exchange partners. We based these choices on setting a manageable horizon of network observability and selecting firms whose actions could be reasonably monitored by the focal firm (e.g., Friedkin 1983). At the same time, because the focal firm was not directly connected to any firm in the two above-noted communities, interpreting the strategic rationale behind their acts could pose a challenge. We found that the effects of these variables, while positive, were substantially weaker than the effect of the firm's direct partners entering into bridging ties $(p<0.10$ and insignificant in some models). Additionally, the effect of direct partners remained significant even in the presence of these additional variables. These results allow us to conclude that while imitation is possible, its effect is weaker than that of dependence and does not offset the impact of changes in interfirm dependence.

Consistent with the theory of dependence-based pressures, we also found that the focal firm's prior bridging ties partly stimulate its partners to form bridging ties. Our complementary analyses showed, however, that the magnitude of this mediation effect is very small. This is not surprising because the actions of the firm's partners are determined not just by the dependence pressures stemming from the focal firm (i.e., a single partner), but also by the actions of their other partners. Furthermore, taking a shorter time window for the firm's prior bridging ties - thereby reducing the lead time for the mediation effect to occur - did not change the 
estimates of incentives and opportunity. This suggests that the partial mediation effect between the firm's prior bridging ties and value-distribution incentives has no significant bearing on the predicted main effects.

In situations where the focal firm and its partners bridge to the same third firm, the dependence mechanism could be partly confounded with simple triadic closure. To account for this effect, we re-estimated our models after eliminating the counts of new bridging ties from the dependent variable that resulted in the formation closed triads. Such cases were rare in our data: across the entire panel, there were only 37 observations (about $2 \%$ of all newly formed bridging ties over 1991-2005) in which a new bridging tie would produce a fully connected triplet. When we re-ran our analyses dropping these from the dependent variables, our key results remained intact.

Hypothesis 3 focused on the possibility that firms may have different levels of structural opportunity to enter into bridging ties. We anticipated that as the structural opportunity for bridging (the availability of bridging contacts relative to local contacts) increases, a firm's propensity to form new bridging ties will increase as well. The effect of Potential bridging partners is significant and positive, thereby supporting Hypothesis 3. We find, specifically, that a one standard-deviation increase in the opportunity variable will result in a 191\% increase in the number of new bridging ties formed by a typical firm. In absolute terms, this effect is roughly equivalent to one extra tie per firm. While our theory predicted independent effects of a firm's incentives and opportunity, we also tested for possible interaction among these factors, investigating whether firms that scored high on all factors simultaneously might show the greatest propensity to form new bridging ties. Our results did not support this possibility. It is important to note that models estimating the count of newly formed bridging ties relative to all newly formed ties (Models 8 and 9) and those that control for newly formed local ties (Models 3 and 6) produce consistent results across all three hypotheses. This indicates that the incentives and opportunities for bridging can drive not only the absolute numbers of bridging ties formed, but also their proportion in the network. A more detailed analysis of the relative trends in the formation of bridging and local ties, however, would also incorporate the incentives and opportunities for firm's entering into local ties. ${ }^{20}$

\footnotetext{
${ }^{20}$ In a set of complementary tests, we compared the model results for bridging ties to those for local and all ties (both local and bridging). Chow tests on linear models revealed significant differences across the models, confirming the distinct nature of bridging relationships and their antecedents.
} 
Finally, in Models 10 and 11 we used logit models to investigate the effects of incentives and opportunities on the likelihood that a firm will form at least one new bridging tie in the following year (with and without Compustat controls, respectively). Because our goal here is to differentiate between bridging and nonbridging firms, the model is estimated without firm-level fixed effects to preserve firms that do not form any bridging ties over the observation period. Results confirm the previously established effects for all Hypotheses.

\section{Robustness Tests}

In a series of tests, we verified the robustness of the previously reported results to missing partnership data, as well as to alternative methods of constructing the interfirm network and modeling the dynamics of interfirm tie formation. To investigate whether the dynamics of bridging ties could be sensitive to incomplete SDC partnership data (Lavie 2007; Lavie and Rosenkopf 2006; Schilling 2009), we conducted several auxiliary analyses. First, we reconstructed the networks using SDC data only on joint ventures in which one of the parties was a publicly traded company. Our exploratory analyses indicated that SDC is more comprehensive in covering joint ventures, which translates into a more complete network structure. Using the network of joint-venture ties, we subsequently reran all our network partitioning procedures and re-estimated the statistical models. Our analysis produced results similar to those on the entire partnership network. Second, we collected data on partnerships in the computer industry over the period 1991-2002 using two alternative sources: the MERITCATI database and the Zephyr databases from Bureau van Dijk (Gomes-Casseres et al. 2006; Schilling 2009). Right-censoring in 2002 was dictated by data availability. Our subsequent comparisons indicated that - while being substantially larger due to the inclusion of a greater number of firms - the SDC network was no more likely than the CATI/Zephyr network to omit data at the firm level. In particular, both networks showed largely consistent community structures in terms of robustness (as indicated by similar modularity scores) and the distribution of individual firms across network communities. Furthermore, modeling the formation of bridging ties on the CATI/Zephyr network data produced similar statistical results.

Third, we performed a set of simulation experiments to further ensure that our results are not sensitive to missing data. Specifically, we simulated a random deletion of up to $50 \%$ of partnership ties in each time period and subsequently replicated our complete analyses. Even after such significant data compromises, the overall pattern of results remained unchanged. Importantly, these results echo the findings of prior studies 
demonstrating that the macro-scale dimensions of social networks are quite resilient to data incompleteness (Kossinets 2006) or random tie removal (Albert and Barabasi 2002). It also confirms conclusions of earlier research regarding SDC data, which suggested that by virtue of sampling on ties, rather than firms, the SDC data structure is robust in preserving critical network properties (Schilling 2009: 257).

In addition, to verify whether our results were robust to the choice of a five-year moving window in modeling tie formation dynamics, we re-ran all our analytic procedures and statistical models on networks with tie duration set to 3, 4, 6, and 7 years. Also, rather than tracing the network's evolution in half-year increments, we applied a one-year resolution, effectively obtaining 15 observation periods between 1991 and 2005. These analyses produced results that were highly consistent with those reported here. Further, we left-censored our data at 1986 because extant empirical work shows that the formation of interorganizational partnerships in the computer industry was less frequent in the 1980s than in the following decade (e.g., Gomes-Casseres et al. 2006; Gulati 1995). Our analysis of the SDC data indicated that compared to the study's timeframe of 1991-2005, the average annual count of newly formed partnerships over 1986-1990 was fifteen times lower. Annual networks mapped for 1986-1990 were 14 times smaller on average than those for 1991-2005, and two and a half times less likely to show a large main component. Similarly, tracing the CATI/Zephyr network back to 1966, we found that only in 1986 did the network manage to acquire a main component larger than a dyad. These auxiliary analyses thus indicated that the network's global architecture did not start to take shape until the early 1990s, confirming that our study's observation timeframe captured the social system's structure since its early inception.

Finally, the theory advanced in this paper emphasized the role of networks as pipes that enable firms' access to knowledge and resources. This is line with emphasis in prior research conducted in the context of hightechnology sectors (Hagedoorn 1993) and the computer industry specifically (e.g., Lee 2007; Yang et al. 2010). Still, we conducted additional tests for the role of firm visibility in the formation of bridging ties, which would suggest that highly central (and thus visible) firms would accumulate a disproportionate number of ties (Albert and Barabasi 2002). Tests for the presence of power-law distribution and preferential attachment (Clauset et al. 2009), however, did not support visibility as a central driver in the formation of new bridging ties. This finding further substantiated this study's theoretical focus on resource flows in networks. 


\section{DISCUSSION}

Extending current research that has provided valuable insights into the consequences of bridging ties, this paper has explored the determinants of bridging ties. Using a network of strategic partnerships in the computer industry, we found that the formation of bridging ties can be understood as a function of the incentives and opportunities of the surrounding network context. Specifically, we showed that the dynamics of proximate network structures shape the formation of bridging ties, likely by changing the value-creation and value-distribution incentives for bridging. Value-creation incentives lie in a firm's ability to recombine insights from newly formed bridging ties with those from existing bridging relationships and to deliver value from such recombination by exploiting a dense local network. Hence, firms that combine sparse, open networks with dense, closed networks show the greatest propensity to enter into new bridging ties. With respect to value-distribution incentives, when a firm's partners enter into bridging ties, it likely exerts dependence pressures on the focal firm as the partners obtain better access to new information and knowledge. This, in turn, can create strong incentives for the focal firm to also enter into new bridging ties in order to reinstitute the more favorable dependence status quo. In addition, the evolving global network structure shapes a firm's opportunity for fortuitous bridging encounters. A global network structure that offers greater opportunities for bridging contacts leads the firm to form a greater number of new bridging ties because it allows for a higher chance of extended contact.

Our study contributes to both organizational theory and economic sociology. First, we contribute to the broad literature on the structural embeddedness of economic action (Granovetter 1985; Mizruchi 1992) by exploring the evolutionary dynamics of social structure. In this regard, we supplement the stream of studies highlighting the role of micro-level behaviors in shaping macro-level structures (Coleman 1990; Giddens 1984). More specifically, prior research has found that bridging ties are a critical determinant of macro-level structures: they can tie cohesive network communities together into a small-world social system; impact the availability of entrepreneurial opportunities in the network; and affect the stratification of social systems (Buskens and Van de Rijt 2008). Thus, understanding the determinants of bridging ties, which has been the thrust of this study, sheds additional light on the complex, multi-level dynamics of how complex social systems arise and evolve.

Second, we contribute to the structural theory of action (Burt 1992; Coleman 1990) by showing how social structure - by virtue of shaping the incentives and opportunities for action - constrains and enables 
individual action. This study examines how the dynamics of proximate network structures may condition actors' interest for entering into new bridging ties. These dynamics can change the value-creation and value-distribution incentives for bridging, thus indirectly patterning the micro-level action of forming bridging ties. The global features of the evolving network, in turn, constrain or enable the formation of bridging ties directly by shaping the structural opportunities for action.

Taken together, these contributions extend the recent work on the evolutionary dynamics of networks. In particular, we advance the ongoing stream of research on the endogenous evolution of networks that focuses on how preexisting network structures can shape the formation of new structures in a dynamic fashion (Gulati and Gargiulo 1999; Rosenkopf and Padula 2008; Zaheer and Soda 2009). Our study offers a novel set of insights to this line of work by recognizing how the distinct proximate and global levels of network structure can independently determine the incentives and opportunities for structural action. Furthermore, while much of the existing research focuses on how network structures can constrain action by reinforcing patterns of local clustering within network communities, this paper points to the fact that evolving social structures can enable extended contact across network communities. We further demonstrate that the propensities for extended contact can vary across firms depending on the structure of incentives and opportunities afforded by the very social system of relationships in which the focal firm is embedded.

Finally, we contribute to the stream of research on the consequences of bridging ties (Granovetter 1973; McEvily and Zaheer 1999; Reagans and McEvily 2003) by showing that the existence of ties spanning distinct network communities should not be taken for granted, but rather be understood as an endogenous outcome that can be explained, in part, by the incentives and opportunities for bridging. Because bridging ties serve as critical leads into brokerage positions (Burt, 1992), this study also provides an introductory set of tools to analyze the systematic determinants of brokerage. Thus, scholars can delve more deeply into whether the differential antecedents of brokerage also translate into differential returns associated with these positions. Finally, we add to studies of complex systems by suggesting that the emergence of bridging ties and the complex systems they engender - a process often relegated to a set of random perturbations (Watts and Strogatz 1998) - may also be understood in part as a function of the interplay between social structure and individual action. 
The theory advanced in this paper requires one important boundary condition. As Giddens (1984: 308) noted, 'constraints do not 'push' anyone to do anything if he or she has not already been 'pulled.' In other words, an account of purposive conduct is implied even when the constraints limiting courses of action are very severe." The theoretical premise of this study is that firms' general purposive conduct toward entering into bridging ties is dictated by the high dynamism and strong knowledge focus of the industry context. In a system where a firm's survival hinges on access to and recombination of novel inputs, the incentives and opportunities of the surrounding social structure work to increase or decrease the feasibility of this generally desirable course of action. In our exploratory investigations that combined computer simulations with analyses of longitudinal network data across seven industries, we found empirical support for this claim. We found, specifically, that in highly dynamic and knowledge-oriented industries (such as microelectronics and telecommunications, where the ratio of firms' aggregate R\&D expenses to aggregate assets was high), firms exhibited a substantially greater propensity for extended contact than in other industries (such as chemicals or automotive, where the ratio of R\&D expenses to firms' overall assets was low). Because the baseline premise of purposive conduct is critical for structural constraints to shape action, we expect that our findings regarding the role of structural incentives and opportunities in shaping the formation of bridging ties will generalize more easily to dynamic and knowledgeoriented industries. In contrast, we expect that the effects of structural parameters on firms' propensity to form bridging ties will be weaker in slow-paced and less technology-focused industries.

No less important is the fact that the evolutionary dynamics of the global network over time can alter the overall degree of pull toward the formation of bridging ties within a single industry. That is, notwithstanding the significant cross-sectoral variations, some industrial settings may display substantial variability with respect to the degree to which they enable or constrain the formation of bridging ties over time. For example, studies of the computer industry suggest that while the strong community structure and the heterogeneous knowledge landscape associated with these communities enabled the formation of bridging ties in the early 1990s, the excessive formation of bridging ties in the following decade squeezed out the very diversity that these ties were designed to harness, thus constraining the formation of new bridges (Gulati et al. 2011). The dynamics of global network structure, therefore, can affect not just the opportunities for bridging as this paper established, but also the general, industry-wide incentives for doing so as reflected in the changing diversity of the available 
knowledge base. Our study complements this line of inquiry by demonstrating the critical firm-level variations in the incentives and opportunities for bridging. Taken together, this and prior studies suggest that the role structural embeddedness in shaping action represents a complex effect that can (i) vary significantly across different industrial settings; (ii) be closely intertwined with the distinct temporal phases of network evolution within a given industrial setting; and (iii) exhibit substantial variation due to the incentives and opportunities faced by a single firm at a given point in time.

In this paper, we examined the role of structural incentives and opportunities in firm's forming bridging ties, while controlling for a range of firm-specific characteristics. Other studies could extend this argument to the internal resource endowments of firms (see e.g., Ahuja 2000b) or the dynamics of market stratification (Baum et al. 2003). Another useful lens would be to consider possible dyad-level factors in the bridging tie matching process. Also, although this paper advances our understanding of the link between structure and action by examining the determinants of structural network positions, future research could explore the precise mechanisms by which network structure affects actors' outcomes. While a great deal of research exists on the link between bridging ties and the outcomes they generate, we still know very little about what leads certain actors to use bridging ties effectively. Thus, the link between the structure of an actor's network and the process of facilitating or curbing resource flows among different network neighborhoods still remains to be explored.

\section{References}

Ahuja, G. 2000a. Collaboration networks, structural holes, and innovation: A longitudinal study. Admi. Sci. Quart. 45(3) 425455.

Ahuja, G. 2000b. The duality of collaboration: Inducements and opportunities in the formation of interfirm linkages. Strat. Management J. 21(3) 317-343.

Ahuja, G., F. Polidoro, W. Mitchell. 2009. Structural hompohily or social asymmetry? The formation of alliances by poorly embedded firms. . Strat. Management J. 30 941-958.

Ahuja, G., G. Soda, A. Zaheer. 2011. The Genesis and Dynamics of Organizational Networks. Org. Sci. Forthcoming. Albert, R., A.L. Barabasi. 2002. Statistical mechanics of complex networks. Reviews of Modern Physics T4(1) 47-97.

Aldrich, H.E. 1979. Organizations and environments. Prentice Hall, Engelwood Cliffs, N.J.

Aldrich, H.E. 1982. The origins and persistence of social networks. P.V. Marsden, N. Lin, eds. Social structure and network analysis. Sage Publications, Beverly Hills, CA, 281-293.

Anand, B.N., T. Khanna. 2000. Do firms learn to create value? The case of alliances. Strat. Management J. 21(3) 295-315.

Arrow, K.J. 1974. The limits of organization, 1 ed. Norton, New York.

Baker, W.E. 1984. The social structure of a national securities market. Amer. J. of Sociology 89(4) 775-811.

Baker, W.E., R.R. Faulkner. 1993. The social organization of conspiracy: Illegal networks in the heavy electrical equipment industry. Amer. J. of Sociology 58(6) 837-860.

Baum, J., B. McEvily, T. Rowley. 2010. Better with age? Tie longevity and the performance implications of bridging and closure. Org. Sci. In press(Published online before print August 20, 2010, DOI:10.1287/orsc.1100.0572.) 1-17.

Baum, J.A.C., T.J. Rowley, A.V. Shipilov, Y.-T. Chuang. 2005. Dancing with strangers: Aspiration performance and the search for underwriting syndicate partners. Admi. Sci. Quart. 50(4) 536-575. 
Baum, J.A.C., A.V. Shipilov, T.J. Rowley. 2003. Where do small worlds come from? Industrial and Corporate Change 12(4) 697725.

Belsey, D.A., E. Kuh, R.E. Welsch. 1980. Regression Diagnostics: Identifying Influential Data and Sources of Collinearity. Wiley, New York.

Bidwell, M., I. Fernandez-Mateo. 2007. Relationship duration and returns to brokerage in the staffing sector. Working paper Blau, P.M. 1977. Inequality and heterogeneity: A primitive theory of social structure. Free Press, New York.

Blau, P.M. 1994. Structural contexts of opportunities. University of Chicago Press, Chicago.

Blau, P.M., J.E. Schwartz. 1984. Crosscutting Social Circles. Academic Press, Orlando.

Bonacich, P. 1972. Technique for analyzing overlapping memberships. H. Costner, ed. Sociological methodology. Jossey-Bass, San Francisco, 176-185.

Bradach, J.L., R.G. Eccles. 1989. Price, authority, and trust: From ideal types to plural forms. Annual Review of Sociology $1597-$ 118.

Bresnahan, T., S. Greenstein. 1999. Technological competition and the structure of the computer industry. Journal of Industrial Economics XLVII 1-39.

Bresnahan, T.F. 1999. New Modes of Competition: Implications for the Future Structure of the Computer Industry. T.M. Lenard, J.A. Eisenach, eds. Competition, Innovation and the Microsoft Monopoly: Antitrust in the Digital Marketplace. Kluwer, Norwell, MA, 155-209.

Bresnahan, T.F. 2000. Competition Cooperation, and Predation in Innovative Industries "Fighting Cartels - Why and How?" The 3RD Nordic Competition Policy Conference, Stockholm.

Burt, R.S. 1982. Toward a structural theory of action : Network models of social structure, perception, and action. Academic Press, New York.

Burt, R.S. 1992. Structural holes: The social structure of competition. Harvard University Press, Cambridge, MA.

Burt, R.S. 2005. Brokerage and Closure: An Introduction to Social Capital. Oxford University Press, New York.

Burt, R.S. 2008. Information and structural holes: Comment on Reagans and Zuckerman. Industrial and Corporate Change.

Buskens, V., A. Van de Rijt. 2008. Dynamics of networks if everyone strives for structural holes. Amer. J. of Sociology 114(2)

371-407.

Cameron, A.C., P.K. Trivedi. 1998. Regression Analysis of Count Data. Cambridge University Press, Cambridge.

Casciaro, T. 2003. Determinants of governance structures in alliances: The role of strategic, task, and partner uncertainties.

Industrial and Corporate Change 12(6) 1223-1251.

Chung, S., H. Singh, K. Lee. 2000. Complementarity, status similarity and social capital as drivers of alliance formation. Strat. Management J. 21(1) 1-22.

Clauset, A., C.R. Shalizi, M.E.J. Newman. 2009. Power-law distributions in empirical data. SLAM Review 51 661-703.

Coleman, J.S. 1990. Foundations of Social Theory. Harvard University Press, Cambridge, MA.

Cook, K.S. 1977. Exchange and power in networks of interorganizational relationships. Sociological Quarterly 18 62-82.

Danon, L., A. Diaz-Guilera, J. Duch, A. Arenas. 2005. Comparing community structure identification. Journal of Statistical Mechanics: Theory and Experiment P09008.

Davies, A., T. Brady, M. Hobday. 2007. Organizing for solutions: Systems seller vs. systems integrator. Industrial Marketing Management 36 183-193.

Davis, G.F., M. Yoo, W.E. Baker. 2003. The small world of the American corporate elite, 1982-2001. Strategic Organization 1(3) 301-326.

Davis, J.A. 1967. Clustering and structural balance in graphs. Human Relations 30 181-187.

Dedrick, J., K.L. Kraemer. 2005. The impacts of IT on firm and industry structure: The personal computer industry. California Management Review 47(3) 122-142.

DiMaggio, P. 1992. Nadel's Paradox revisited: Relational and cultural aspects of organizational structure. N. Nohria, R.G.

Eccies, eds. Networks and Organizations: Structure, Form, and Action. Harvard Business School Press, Boston.

DiMaggio, P.J., W.W. Powell. 1983. The iron cage revisited: Institutional isomorphism and collective rationality in organizational fields. American Sociological Review 48(2) 147-160.

Doreian, P. 1989. Models of network effects on social actors. L.C. Freeman, D.R. White, K. Romney, eds. Research Methods in Social Analysis. George Mason University Press, Fairfax, VA, 295-317.

Eisenhardt, K.M., B.N. Tabrizi. 1995. Accelerating adaptive processes: Product innovation in the global computer industry. Admi. Sci. Quart. 41(1) 84-100.

Emerson, R.M. 1962. Power-dependence relations. American Sociological Review(27) 31-41.

Emerson, R.M. 1964. Power-dependence relations: Two experiments. Sociometry 27(3) 282-298.

Feld, S.L., W.C. Carter. 1998. When desegregation reduces interratial contact: A class size paradox for weak ties. Amer. J. of Sociology 103(5) 1165-1186.

Fernandez-Mateo, I. 2007. Who pays the price of brokerage? Transferring constraint through price setting in the staffing sector. American Sociological Review 72 291-317.

Festinger, L., S. Schachter, K.W. Burt. 1950. Social Pressures in Informal Groups. Stanford University Press, Stanford, CA. Friedkin, N.E. 1983. Horizons of observability and limits of informal control in organizations. Social Forces 62(1) 54-77. 
Giddens, A. 1984. The Constitution of Society: Outline of the Theory of Structure. University of California Press, Berkeley, CA. Girvan, M., M.E.J. Newman. 2002. Community structure in social and biological networks. Proceedings of the National Academy of Sciences 99 7821-7826.

Gomes-Casseres, B., J. Hagedoorn, A.B. Jaffe. 2006. Do alliances promote knowledge flows? Journal of Financal Economics 80 $5-33$.

Gould, R.V., R.M. Fernandez. 1989. Structures of mediation: A formal approach to brokerage in transaction networks. Sociological Methodology 19 89-126.

Granovetter, M. 1983. The strength of weak ties: A network theory revisited. Sociological Theory 1201-233.

Granovetter, M. 1985. Economic action and social structure: The problem of embeddedness. Amer. J. of Sociology 91 (3) 481510.

Granovetter, M.S. 1973. The strength of weak ties. Amer. J. of Sociology 78(6) 1360-1380.

Greif, A. 1989. Reputation and coalitions in medieval trade: Evidence on the Maghribi traders. Journal of Economic History 49(4) 857-882.

Grove, A. 1996. Only the Paranoid Survive. HarperCollins Business, New York.

Guimera, R., L. Amaral. 2005. Cartography of complex networks: modules and universal roles. Journal of Statistical Mechanics 2 $1-13$.

Gulati, R. 1995. Social structure and alliance formation patterns: A longitudinal analysis. Admi. Sci. Quart. 40(4) 619-652.

Gulati, R. 1999. Network location and learning: The influence of network resources and firm capabilities on alliance formation. Strat. Management J. 20(5) 397-420.

Gulati, R., M. Gargiulo. 1999. Where do interorganizational networks come from? American Journal of Sociology 104(5) 14391493.

Gulati, R., M. Sytch. 2007. Dependence asymmetry and joint dependence in interorganizational relationships: Effects of embeddedness on exchange performance. Admi. Sci. Quart. 52 32-69.

Gulati, R., M. Sytch, P. Mehrotra. 2008. Breaking Up is Never Easy: Planning for exit in a strategic alliance. California Management Review 50(4) 147-163.

Gulati, R., M. Sytch, A. Tatarynowicz. 2011. The rise and fall of small worlds: Exploring the evolutionary dynamics of social structure. Org. Sci.(published online before print December 29, 2010, DOI:10.1287/orsc.1100.0592.).

Hagedoorn, J. 1993. Understanding the rationale of strategic technology partnering: Interorganizational modes of cooperation and sectoral differences. Strat. Management J. 14(5) 371-385.

Hall, B., A. Jaffe, M. Trajtenerg. 2001. The NBER Patent citation data file: Lessons, insights, and methodological tools. National Bureau of Economic Research.

Hargadon, A., R.I. Sutton. 1997. Technology brokering and innovation in a product development firm. Admi. Sci. Quart. 42(4) 716-749.

Haunschild, P.R., C. Beckman. 1998. When do interlocks matter?: Alternate sources of information and interlock influence. Admi. Sci. Quart. 43(4) 815-844.

Haunschild, P.R., A.S. Miner. 1997. Modes of interorganizational imitation: The effects of outcome salience and uncertainty. Admi. Sci. Quart. 42(3) 472-500.

Hausman, J.A. 1978. Specification tests in econometrics. Econometrica 46 1251-1271.

Hausman, J.A., B. Hall, Z. Griliches. 1984. Econometric models for count data with an application to the patents-R\&D relationship. Econometrica 52(4) 909-938.

Hayek, F. 1945. The use of knowledge in society. Ameri. Econ. Review 35(September) 519-530.

Hilbe, J.M. 2007. Negative Binomial Regression. Cambridge University Press, Cambridge, UK.

Jensen, M.C. 2003. The role of network resources in market entry: Commerical banks' entry into investment banking, 1991 1997. Admi. Sci. Quart. 48(3) 466-497.

Kim, H., R.E. Hoskisson, W.P. Wan. 2004. Power dependence, diversification strategy, and performance in keiretsu member firms. Strat. Management J. 25(7) 613-636.

Knoke, D. 2009. Playing well together: Creating corporate social capital in strategic alliance networks. American Behavioral Scientist 52 1690-1708.

Kogut, B. 1988. Joint ventures: Theoretical and empirical perspectives. Strategic Management Journal 9 319-332.

Kogut, B., G. Walker. 2001. The small world of Germany and the durability of national networks. American Sociological Review $66317-335$.

Kossinets, G. 2006. Effects of missing data in social networks. Social Networks 28 247-268.

Lavie, D. 2007. Alliance portfolios and firm performance: A study of value creation and appropriation in the U.S. software industry. Strat. Management J. 28(12) 1187-1212.

Lavie, D., L. Rosenkopf. 2006. Balancing exploration and exploitation in alliance formation. Acad. of Management J. 49(4) 797818.

Lee, G.K. 2007. The significance of network resources in the race to enter emerging product markets: The convergence of telephony communications and computer networking, 1989-2001. Strategic Management Journal 28 17-37. 
Li, S.X., T.J. Rowley. 2002. Inertia and evaluation mechanisms in interorganizational partner selection: Syndicate formation among U.S. investment banks. Acad. of Management J. 45(6) 1104-1118.

Lin, N. 2001. Social Capital: A Theory of Social Structure and Action Cambridge University Press, Cambridge.

Lincoln, J.R., M.L. Gerlach. 2004. Japan's Network Economy. Cambridge University Press, New York.

Macy, M. 1990. Learnig theory and the logic of critical mass. American Sociological Review 55 809-826.

Malerba, F., L. Orsenigo. 1996. The Dynamics and Evolution of Industries. Industrial and Corporate Change(5) 51-87.

Marsden, P.V., N.E. Friedkin. 1993. Network studies of social influence. Sociological Methods Research 22 127-151.

McEvily, B., J. Jaffee, M. Tortoriello. 2011. Not all bridging ties are equal: Network imprinting and firm growth in the Nashville legal industry 1933-1978. Org. Sci. Forthcoming.

McEvily, B., A. Zaheer. 1999. Bridging ties: A source of firm heterogeneity in competitive capabilities. Strat. Management J. 20(12) 1133-1156.

McPherson, J.M., L. Smith-Lovin, J.M. Cook. 2001. Birds of a feather: Homophily in social networks. Annual Review of Sociology 27 415-444.

Mizruchi, M.S. 1989. Similarity of political behavior among large American corporations. Amer. J. of Sociology 95(2) $401-424$.

Mizruchi, M.S. 1992. The Structure of Corporate Political Action: Interfirm Relations and Their Consequences. Harvard University Press, Cambridge, MA.

Mizruchi, M.S., J. Galaskiewicz. 1993. Networks of interorganizational relationships. Sociological Methods and Research 22 46-70.

Mowery, D.C., J.E. Oxley, B.S. Silverman. 1998. Technological overlap and interfirm cooperation: implications for the resource-based view of the firm. Research Policy 27(5) 17.

Newman, M.E.J. 2004. Detecting community structure in networks. European Physical Journal B 38 321-330.

Obsfeld, D. 2005. Social networks, the Tertius Iungens orientation, and involvement in innovation. Admi. Sci. Quart. 50(1)

100-130.

Owen-Smith, J., W.W. Powell. 2004. Knowledge networks in the Boston biotechnology community. Org. Sci. 15(1) 5-21.

Pfeffer, J., G. Salancik. 1978. The External Control of Organizations. Harper and Row, New York.

Podolny, J. 1994. Market uncertainty and the social character of economic exchange. Admi. Sci. Quart. 39(3) 458-483.

Podolny, J. 2001. Networks as the pipes and prisms of the market. Amer. J. of Sociology 107(1) 33-60.

Porac, J.F., H. Thomas, F. Wilson, D. Paton, A. Kanfer. 1995. Rivalry and the industry model of Scottish knitwear producers. Admi. Sci. Quart. 40 203-227.

Porter, M.A., P.J. Mucha, M.E.J. Newman, A.J. Friend. 2007. Community structure in the United States House of

Representatives. Physica A 386 414-438.

Powell, W.W. 1996. Interorganizational collaboration in the biotechnology industry. Journal of Institutional and Theoretical

Economics 152 197-215.

Powell, W.W., D.R. White, K.W. Koput, J. Owen-Smith. 2005. Network dynamics and field evolution: The growth of interorganizational collaboration in the life sciences. Amer. J. of Sociology 110(4) 1132-1205.

Rao, H., H.R. Greve, G.F. Davis. 2001. Fool's gold: Social proof in the initiation and abandonment of coverage by Wall Street analysts. Admi. Sci. Quart. 46 502-526.

Reagans, R., B. McEvily. 2003. Network structure and knowledge transfer: The effects of cohesion and range. Admi. Sci. Quart. 48 240-267.

Reagans, R., E. Zuckerman. 2008. Why knowledge does not equal power: the network redundancy trade-off. Industrial and Corporate Change 17(5) 904-944.

Reagans, R., E. Zuckerman, B. McEvily. 2004. How to Make the Team: Social Networks vs. Demography as Criteria for Designing Effective Teams. Admi. Sci. Quart. 49(1) 101-133.

Reagans, R., E.W. Zuckerman. 2001. Networks, diversity, and productivity: The social capital of corporate R\&D teams. Org. Sci. 12(4) 502-517.

Rogers, E.M. 2003. Diffusion of Innovations, 5th ed. Free Press, New York.

Rogers, W.H. 1993. Regression standard errors in clustered samples. Stata Technical Bulletin sg17(13) 19-23.

Rosenkopf, L., A. Metiu, V.P. George. 2001. From the bottom up? Technical committee activity and alliance formation. Admi. Sci. Quart. 46(4) 748-772.

Rosenkopf, L., G. Padula. 2008. Investigating the microstructure of network evolution: Alliance formation in the mobile communications industry. Org. Sci. 19(5) 669-687.

Rothaermel, F.T. 2001. Incumbent's advantage through exploiting complementary assets via interfirm cooperation. Strat. Management J. 22(6/7) 687-699.

Rowley, T., D. Behrens, D. Krackhardt. 2000. Redundant governance structures: An analysis of structural and relational embeddedness in the steel and semiconductor industries. Strat. Management J. 21(3) 369-386.

Ryall, M.D., O. Sorenson. 2007. Brokers and competitive advantage. Management Science 53(4) 566-583.

Rytina, S., D.L. Morgan. 1982. The arithmetic of social relations: The interplay of category and network. The American Journal of Sociology 88(1) 88-113.

Salancik, G.R. 1995. Review essay - Wanted: A good network theory of organization. Admi. Sci. Quart. 40(2) 345-349. 
Saxenian, A. 1994. Regional Advantage: Culture and Competition in Silicon Valley and Route 128. Harvard University Press, Cambridge, MA.

Schilling, M. 2009. Understanding alliance data. Strat. Management J. 30(3) 233-260.

Schilling, M., C.C. Phelps. 2007. Interfirm collaboration networks: The impact of large-scale network structure on firm innovation. Management Science 53(7) 1113-1126.

Schumpeter, J. 1934. The Theory of Economic Development: An Inquiry into Profits, Capital, Credit, Interest, and the Business Cycle. Harvard University Press, Cambridge, MA.

Shane, S.A. 1996. Hybrid Organizational Arrangements and Their Implications for Firm Growth and Survival: A Study of New Franchisors. The Academy of Management Journal 39(1) 216-234.

Shepherd, C., P.K. Ahmed. 2000. From product innovation to solutions innovation: A new paradigm for competitive advantage. European Journal of Innovation Management 3(2) 100-106.

Shipilov, A.V., S.X. Li. 2011. The missing link: The effect of customers on the formation of relationships among producers in the multiplex triads. Org. Sci. In Press(Published online before print September 15, 2010, DOI:10.1287/orsc.1100.0568) $1-20$.

Simmel, G. 1955. Conflict and the web of group-affiliations. Free Press, New York.

Sorenson, O., T.E. Stuart. 2001. Syndication networks and the spatial distribution of venture capital investments. Amer. J. of Sociology 106(6) 1546-1588.

Stuart, T.E. 1998. Network positions and propensities to collaborate: An investigation of strategic alliance formation in a high-technology industry. Admi. Sci. Quart. 43(3) 668-698.

Thompson, J.D. 1967. Organizations in Action. McGraw-Hill, New York.

Uzzi, B. 1996. The sources and consequences of embeddedness for the economic performance of organizations: The network effect. American Sociological Review 61(4) 674-698.

Uzzi, B. 1997. Social structure and competition in interfirm networks: The paradox of embeddedness. Admi. Sci. Quart. 42

35-67.

Uzzi, B., J. Spiro. 2005. Collaboration and creativity: The small world problem. Amer. J. of Sociology 111(2) 447-504.

Vanneste, B.S., P. Puranam. 2010. Repeated interactions and contractual detail: Identifying the learning effect. Org. Sci. 21(1) 186-201.

Vuong, Q.H. 1989. Likelihood ratio tests for model selection and non-nested hypotheses. Econometrica 57 307-333.

Wang, L., E.J. Zajac. 2007. Alliance or acquisition? A dyadic perspective on interfirm resource combinations. Strat. Management J. 28(13) 1291-1317.

Wasserman, S., K. Faust. 1994. Social Network Analysis: Methods and Applications. Cambridge University Press, Cambridge. Watts, D.J. 1999. Networks, dynamics, and the small-world phenomenon. Amer. J. of Sociology 105(2) 493-527.

Watts, D.J., S.H. Strogatz. 1998. Collective dynamics of small-world networks. Nature 393 440-442.

Wegner, D.M. 1986. Transactive memory: A contemporary analysis of the group mind. G. Mullen, G. Goethals, eds. Theories of group behavior. Springer-Verlag, New York, 185-208.

Wellman, B. 1979. The community question: The intimate networks of East Yorkers. Amer. J. of Sociology 84 1201-1231. Wooldridge, J.M. 1999. Distribution-free estimation of some nonlinear panel data models. Journal of Econometrics 90 77-97. Yang, H., Z. Lin, Y. Lin. 2010. A multilevel framework of firm boundaries: Firm characteristics, dyadic differences, and network attributes. Strat. Management J. 31 237-261.

Zachary, W.W. 1977. An information flow model for conflict and fission in small groups. Journal of Anthropological Research 33 452-473.

Zaheer, A., G.G. Bell. 2005. Benefiting from network position: Firm capabilities, structural holes, and performance. Strat. Management J. 26 809-825.

Zaheer, A., G. Soda. 2009. Network evolution: The origins of structural holes. Admi. Sci. Quart. 54 1-31.

Zuckerman, E.W. 2004. Structural incoherence and stock market activity. American Sociological Review 69(3) 405-432. 
Table 1. Descriptive statistics and correlation matrix

\begin{tabular}{|c|c|c|c|c|c|c|c|c|c|c|c|c|c|c|c|c|c|}
\hline & Variable & Mean & SD & Min & Max & 1 & 2 & 3 & 4 & 5 & 6 & 7 & 8 & 9 & 10 & 11 & 12 \\
\hline$D V$ & New bridging ties in $t+1$ & 0.281 & 0.981 & 0 & 15 & & & & & & & & & & & & \\
\hline 1 & Sales (log) & 8.115 & 2.383 & 0.000 & 12.790 & - & & & & & & & & & & & \\
\hline 2 & Headcount (log) & 3.140 & 2.310 & 0.000 & 11.813 & 0.617 & & & & & & & & & & & \\
\hline 3 & Net income (log) & 10.569 & 0.349 & 0.000 & 11.218 & 0.069 & 0.061 & - & & & & & & & & & \\
\hline 4 & Incumbent firm & 0.937 & 0.243 & 0 & 1 & 0.113 & 0.027 & -0.008 & - & & & & & & & & \\
\hline 5 & Eigenvector centrality & 0.037 & 0.075 & 0.000 & 0.441 & 0.264 & 0.364 & 0.019 & 0.128 & - & & & & & & & \\
\hline 6 & Past bridging experience $(\log )$ & 0.638 & 0.985 & 0.000 & 4.369 & 0.266 & 0.194 & 0.022 & 0.159 & 0.364 & - & & & & & & \\
\hline 7 & Current local ties (log) & 1.632 & 0.878 & 0.000 & 4.190 & 0.334 & 0.301 & 0.009 & 0.481 & 0.613 & 0.567 & & & & & & \\
\hline 8 & Current bridging ties $(\log )$ & 0.743 & 0.880 & 0.000 & 3.951 & 0.269 & 0.130 & 0.025 & 0.219 & 0.497 & 0.623 & 0.696 & & & & & \\
\hline 9 & Network autocorrelation & 0.019 & 0.038 & 0.000 & 0.458 & 0.070 & 0.133 & 0.015 & 0.128 & 0.087 & 0.001 & 0.064 & -0.020 & - & & & \\
\hline 10 & New local ties $(\log )$ & 0.363 & 0.588 & 0.000 & 3.091 & 0.100 & 0.123 & 0.036 & -0.308 & 0.128 & 0.128 & 0.055 & 0.149 & 0.140 & - & & \\
\hline 11 & Bridging ties by dependent firms $(\log )$ & 0.505 & 0.639 & 0.000 & 3.091 & 0.215 & 0.147 & 0.008 & 0.205 & 0.468 & 0.365 & 0.565 & 0.680 & 0.137 & 0.209 & & \\
\hline 12 & Opportunity for bridging $(\log )$ & 5.617 & 1.750 & 0.000 & 6.904 & 0.007 & -0.103 & -0.004 & 0.831 & 0.057 & 0.253 & 0.478 & 0.349 & 0.182 & -0.202 & 0.346 & - \\
\hline
\end{tabular}


Table 2. Negative binomial estimates (Models 1-4); OLS estimates (Models 5-9); Logit estimates (Models 10 and 11)

\begin{tabular}{|c|c|c|c|c|c|c|c|c|c|c|c|}
\hline & $\begin{array}{c}1 \text { (NB) } \\
\text { New bridging ties }\end{array}$ & $\begin{array}{c}2 \text { (NB) } \\
\text { New bridging ties }\end{array}$ & $\begin{array}{c}3 \text { (NB) } \\
\text { New bridging ties }\end{array}$ & $\begin{array}{c}4 \text { (NB) } \\
\text { New bridging ties }\end{array}$ & $\begin{array}{c}\mathbf{5} \text { (OLS) } \\
\text { Std. new br. ties }\end{array}$ & $\begin{array}{c}6 \text { (OLS) } \\
\text { Std. new br. ties }\end{array}$ & $\begin{array}{c}7 \text { (OLS) } \\
\text { Std. new br. ties }\end{array}$ & $\begin{array}{c}8 \text { (OLS) } \\
\text { New br./ all ties }\end{array}$ & $\begin{array}{c}\mathbf{9} \text { (OLS) } \\
\text { New br./ all ties }\end{array}$ & $\begin{array}{c}10 \text { (Logit) } \\
\text { Br. tie in } t+1\end{array}$ & $\begin{array}{c}11 \text { (Logit) } \\
\text { Br. tie in }{ }^{+1}\end{array}$ \\
\hline Constant & $\begin{array}{l}-22.8625^{*} \\
(13.5727)\end{array}$ & $\begin{array}{l}-5.6343 \\
(12.1377)\end{array}$ & $\begin{array}{l}-2.7710 \\
(4.3613)\end{array}$ & $\begin{array}{l}0.4064 \\
(0.3111)\end{array}$ & $\begin{array}{l}-1.2867 \\
(1.2453)\end{array}$ & $\begin{array}{l}-2.2397 * \\
(1.2145)\end{array}$ & $\begin{array}{l}-0.1449 * * * \\
(0.0288)\end{array}$ & $\begin{array}{l}-0.0845 \\
(0.0638)\end{array}$ & $\begin{array}{l}-0.0013 \\
(0.0015)\end{array}$ & $\begin{array}{l}-13.0959 \\
(10.9041)\end{array}$ & $\begin{array}{l}-3.9485^{* * *} \\
(0.3010)\end{array}$ \\
\hline Sales & $\begin{array}{l}0.1185 \\
(0.0821)\end{array}$ & $\begin{array}{l}0.0977 \\
(0.0901)\end{array}$ & $\begin{array}{l}0.0486 \\
(0.0868)\end{array}$ & - & $\begin{array}{l}-0.0282 \\
(0.0201)\end{array}$ & $\begin{array}{l}-0.0365^{*} \\
(0.0196)\end{array}$ & - & $\begin{array}{l}0.0001 \\
(0.0010)\end{array}$ & - & $\begin{array}{l}0.0205 \\
(0.0411)\end{array}$ & - \\
\hline Headcount & $\begin{array}{l}-0.0233 \\
(0.0516)\end{array}$ & $\begin{array}{l}0.0217 \\
(0.0511)\end{array}$ & $\begin{array}{l}0.0143 \\
(0.0510)\end{array}$ & - & $\begin{array}{l}0.0004 \\
(0.0122)\end{array}$ & $\begin{array}{l}-0.0089 \\
(0.0119)\end{array}$ & - & $\begin{array}{l}0.0001 \\
(0.0006)\end{array}$ & - & $\begin{array}{l}0.0062 \\
(0.0391)\end{array}$ & - \\
\hline Net income & $\begin{array}{l}1.9978 \\
(1.2914)\end{array}$ & $\begin{array}{l}0.4586 \\
(1.1506)\end{array}$ & $\begin{array}{l}0.0779 \\
(0.4055)\end{array}$ & - & $\begin{array}{l}0.1189 \\
(0.1173)\end{array}$ & $\begin{array}{l}0.1086 \\
(0.1144)\end{array}$ & - & $\begin{array}{l}0.0080 \\
(0.0060)\end{array}$ & - & $\begin{array}{l}0.8506 \\
(1.0374)\end{array}$ & - \\
\hline Incumbent firm & $\begin{array}{l}-2.4770 * * * \\
(0.3242)\end{array}$ & $\begin{array}{l}-5.0238 * * * \\
(0.8393)\end{array}$ & $\begin{array}{l}-3.0027^{* * *} \\
(0.8579)\end{array}$ & $\begin{array}{l}-5.6753 * * * \\
(0.6843)\end{array}$ & $\begin{array}{l}-1.4310 * * * \\
(0.2295)\end{array}$ & $\begin{array}{l}-0.0317 \\
(0.2301)\end{array}$ & $\begin{array}{l}-0.7808 * * * \\
(0.0657)\end{array}$ & $\begin{array}{l}-0.0859 * * * \\
(0.0117)\end{array}$ & $\begin{array}{l}-0.0415 * * * \\
(0.0035)\end{array}$ & $\begin{array}{l}-2.9634 * * * \\
(0.5607)\end{array}$ & $\begin{array}{l}-3.9602 * * * \\
(0.4504)\end{array}$ \\
\hline Eigenvector centrality & $\begin{array}{l}-4.5846 * * * \\
(1.1407)\end{array}$ & $\begin{array}{l}-5.5891 * * * \\
(1.1937)\end{array}$ & $\begin{array}{l}-5.5512 * * * \\
(1.1956)\end{array}$ & $\begin{array}{l}-6.6598 * * * \\
(1.1356)\end{array}$ & $\begin{array}{l}-8.0098 * * * \\
(0.9293)\end{array}$ & $\begin{array}{l}-9.2429 * * * \\
(0.9071)\end{array}$ & $\begin{array}{l}-5.2181 * * * \\
(0.3577)\end{array}$ & $\begin{array}{l}-0.2009 * * * \\
(0.0476)\end{array}$ & $\begin{array}{l}-0.1231 \text { *** } \\
(0.0189)\end{array}$ & $\begin{array}{l}-10.1959 * * * \\
(1.5939)\end{array}$ & $\begin{array}{l}-11.6367 * * * \\
(1.5092)\end{array}$ \\
\hline Past bridging experience & $\begin{array}{l}-0.2054 \\
(0.1333)\end{array}$ & $\begin{array}{l}-0.2636 \\
(0.1648)\end{array}$ & $\begin{array}{l}-0.3240 * * \\
(0.1648)\end{array}$ & $\begin{array}{l}-0.3197 * * \\
(0.1536)\end{array}$ & $\begin{array}{l}-0.9830 * * * \\
(0.1240)\end{array}$ & $\begin{array}{l}-0.9239 * * * \\
(0.1209)\end{array}$ & $\begin{array}{l}-1.0186^{* * *} \\
(0.0517)\end{array}$ & $\begin{array}{l}-0.0382 * * * \\
(0.0063)\end{array}$ & $\begin{array}{l}-0.0518^{* * *} \\
(0.0027)\end{array}$ & $\begin{array}{l}0.2945 * * * \\
(0.1118)\end{array}$ & $\begin{array}{l}0.3678^{* * *} \\
(0.0990)\end{array}$ \\
\hline Current local ties & $\begin{array}{l}0.9423 * * * \\
(0.1951)\end{array}$ & $\begin{array}{l}0.5068 * * \\
(0.2087)\end{array}$ & $\begin{array}{l}0.6325 * * * \\
(0.2006)\end{array}$ & $\begin{array}{l}0.8380 * * * \\
(0.1697)\end{array}$ & $\begin{array}{l}0.0786 \\
(0.0722)\end{array}$ & $\begin{array}{l}0.6384 * * * \\
(0.0736)\end{array}$ & $\begin{array}{l}0.0602 * * \\
(0.0248)\end{array}$ & $\begin{array}{l}0.0250 * * * \\
(0.0037)\end{array}$ & $\begin{array}{l}0.0119 * * * \\
(0.0013)\end{array}$ & $\begin{array}{l}1.2109 * * * \\
(0.1739)\end{array}$ & $\begin{array}{l}1.4974 * * * \\
(0.1438)\end{array}$ \\
\hline Current bridging ties & $\begin{array}{l}-0.2077^{*} \\
(0.1204)\end{array}$ & $\begin{array}{l}-1.2559 * * * \\
(0.2310)\end{array}$ & $\begin{array}{l}-1.0805 * * * \\
(0.2165)\end{array}$ & $\begin{array}{l}-1.7320 * * * \\
(0.2045)\end{array}$ & $\begin{array}{l}-1.1376 * * * \\
(0.1195)\end{array}$ & $\begin{array}{l}-0.9870 * * * \\
(0.1166)\end{array}$ & $\begin{array}{l}-1.1924^{* * *} \\
(0.0464)\end{array}$ & $\begin{array}{l}-0.0918^{* * *} \\
(0.0061)\end{array}$ & $\begin{array}{l}-0.0854 * * * \\
(0.0025)\end{array}$ & $\begin{array}{l}-0.8965 * * * \\
(0.2703)\end{array}$ & $\begin{array}{l}-0.7087 * * * \\
(0.2281)\end{array}$ \\
\hline Network autocorrelation & $\begin{array}{l}13.5924 * * * \\
(1.0425)\end{array}$ & $\begin{array}{l}10.5723 * * * \\
(1.1280)\end{array}$ & $\begin{array}{l}10.0475^{* * *} \\
(1.1066)\end{array}$ & $\begin{array}{l}9.1227 * * * \\
(0.9771)\end{array}$ & $\begin{array}{l}10.7384^{* * *} \\
(0.5506)\end{array}$ & $\begin{array}{l}9.7977 * * * \\
(0.5379)\end{array}$ & $\begin{array}{l}3.2766 * * * \\
(0.1611)\end{array}$ & $\begin{array}{l}0.3020 * * * \\
(0.0282)\end{array}$ & $\begin{array}{l}0.1096 * * * \\
(0.0085)\end{array}$ & $\begin{array}{l}0.0337 \\
(1.7494)\end{array}$ & $\begin{array}{l}1.0397 \\
(1.3832)\end{array}$ \\
\hline New local ties & & & $\begin{array}{l}0.8758^{* * *} \\
(0.0864)\end{array}$ & - & - & $\begin{array}{l}1.5072 * * * \\
(0.0579)\end{array}$ & - & - & - & - & - \\
\hline Firm-level fixed effects & Yes & Yes & Yes & Yes & Yes & Yes & Yes & Yes & Yes & - & \\
\hline Period fixed effects & Yes & Yes & Yes & Yes & Yes & Yes & Yes & Yes & Yes & Yes & Yes \\
\hline Current lo. $\times$ Current br. ties & & $\begin{array}{l}0.3538 * * * \\
(0.0882)\end{array}$ & $\begin{array}{l}0.3349 * * * \\
(0.0837)\end{array}$ & $\begin{array}{l}0.5447 * * * \\
(0.0801)\end{array}$ & $\begin{array}{l}0.7047 * * * \\
(0.0605)\end{array}$ & $\begin{array}{l}0.5898 * * * \\
(0.0592)\end{array}$ & $\begin{array}{l}0.7410 * * * \\
(0.0252)\end{array}$ & $\begin{array}{l}0.0436 * * * \\
(0.0031)\end{array}$ & $\begin{array}{l}0.0438 * * * \\
(0.0013)\end{array}$ & $\begin{array}{l}0.2818^{* *} \\
(0.1150)\end{array}$ & $\begin{array}{l}0.2463 * * \\
(0.0999)\end{array}$ \\
\hline Br. ties by dependent firms & & $\begin{array}{l}0.3666 * * \\
(0.1533)\end{array}$ & $\begin{array}{l}0.2535^{*} \\
(0.1519)\end{array}$ & $\begin{array}{l}0.3703 * * * \\
(0.1344)\end{array}$ & $\begin{array}{l}1.1536 * * * \\
(0.0736)\end{array}$ & $\begin{array}{l}0.9474 * * * \\
(0.0722)\end{array}$ & $\begin{array}{l}0.6204 * * * \\
(0.0263)\end{array}$ & $\begin{array}{l}0.0114^{* * * *} \\
(0.0038)\end{array}$ & $\begin{array}{l}0.0066 * * * \\
(0.0014)\end{array}$ & $\begin{array}{l}2.1745 * * * \\
(0.1057)\end{array}$ & $\begin{array}{l}2.3011 * * * \\
(0.0781)\end{array}$ \\
\hline Opportunity for bridging & & $\begin{array}{l}0.6117 * * * \\
(0.1396)\end{array}$ & $\begin{array}{l}0.3485 * * \\
(0.1392)\end{array}$ & $\begin{array}{l}0.6494 * * * \\
(0.1136)\end{array}$ & $\begin{array}{l}0.1751 * * * \\
(0.0362)\end{array}$ & $\begin{array}{l}0.0636^{*} \\
(0.0355)\end{array}$ & $\begin{array}{l}0.1025 * * * \\
(0.0101)\end{array}$ & $\begin{array}{l}0.0097 * * * \\
(0.0019)\end{array}$ & $\begin{array}{l}0.0048 * * * \\
(0.0005)\end{array}$ & $\begin{array}{l}0.3151 * * * \\
(0.0833)\end{array}$ & $\begin{array}{l}0.3733^{* * *} \\
(0.0710)\end{array}$ \\
\hline Obs. & 1926 & 1926 & 1926 & 3083 & 14730 & 14730 & 65502 & 14730 & 65502 & 14730 & 65502 \\
\hline Log-likelihood & $-734.6 * *$ & $-705.4 * * *$ & $-657.6^{* * * *}$ & $-966.7 * * *$ & - & - & - & - & - & $-702.8 * * *$ & $2522.4 * * *$ \\
\hline F-statistic & - & - & & - & $91.0^{* * *}$ & $137.4^{* * *}$ & $268.9^{* * *}$ & $42.7 * * *$ & $197.8^{* * *}$ & - & \\
\hline
\end{tabular}

Notes: Robust standard errors in parentheses; ${ }^{* * *} p<.01,{ }^{* *} p<.05,{ }^{*} p<.10$ 